\title{
Thermodynamics of Nitrogen in Fe-Mn-Al-Si-C Alloy Melts
}

\author{
MIN-KYU PAEK, SAIKAT CHATTERJEE, JONG-JIN PAK, and IN-HO JUNG \\ Thermodynamic behavior of nitrogen in the entire range of the Fe-Mn-Al-Si-C liquid solution \\ was modeled based on the critical evaluation and optimization of all available experimental \\ data. The Gibbs energy of liquid solution was described using the Modified Quasichemical \\ Model (MQM) in the pair approximation, instead of classical Wagner Interaction Parameter \\ Formalism, to consider the strong interactions between species in liquid state. In particular, the \\ dissolution behavior of $\mathrm{N}$ and formation of AlN in the entire ternary and higher order liquids \\ were accurately predicted from the MQM only with binary model parameters of $\mathrm{N}$.
}

DOI: $10.1007 / \mathrm{s} 11663-016-0588-\mathrm{y}$

(C) The Minerals, Metals \& Materials Society and ASM International 2016

\section{INTRODUCTION}

RECENTLY, high alloy steels such as high Mn-Si steel, high Al and TWIP (TWining Induced Plasticity) steels have been developed as next generation advanced high strength steels for automotive applications. High amounts of alloying elements bring great challenges to steelmaking and casting processes; significant corrosion of refractories, new types of non-metallic inclusion formation, high solubility of gas species, and long solidification range. For example, TWIP steel shows an excellent combination of high strength, ductility, and formability over conventional steels by alloying a large amount of $\mathrm{Mn}$ (15 to $20 \mathrm{wt} \mathrm{pct}$ ), $\mathrm{Al}$ (1 to $3 \mathrm{wt} \mathrm{pct}), \mathrm{Si}$ $(\sim 0.3 \mathrm{wt}$ pct $)$, and $\mathrm{C}(0.4$ to $0.6 \mathrm{wt}$ pct $) .{ }^{[1-3]}$ However, Mn significantly increases the $\mathrm{N}$ solubility in liquid iron, while decreases the melting temperature of the steels down to near $1723 \mathrm{~K}\left(1450{ }^{\circ} \mathrm{C}\right) \cdot{ }^{[4]} \mathrm{In}$ addition, the aluminum nitride, AlN, can be easily formed by the strong affinity of $\mathrm{Al}$ with $\mathrm{N}$ in the high-Mn and high- $\mathrm{Al}$ alloyed liquid steels. ${ }^{[5]}$ Although the AlN inclusion is considered as a detrimental phase for the surface quality as well as the mechanical property of the final steel product, the critical $\mathrm{N}$ content for the AlN formation during cooling and solidification of high alloyed steels is less predictable due to the lack of the thermodynamic information.

MIN-KYU PAEK, Postdoctoral Fellow, and IN-HO JUNG, Associate Professor, are with the Department of Mining and Materials Engineering, McGill University, Montreal, QC H3A 0C5, Canada. Contact e-mail: in-ho.jung@mcgill.ca SAIKAT CHATTERJEE, Graduate Student, formerly with the Department of Mining and Materials Engineering, McGill University, is now with the Department of Materials Science and Engineering, University of Toronto, ON M5S 3ES, Canada. JONG-JIN PAK, Professor, is with Department of Materials Engineering, Hanyang University, ERICA, Ansan 426-791, Republic of Korea.

Manuscript submitted March 13, 2015.

Article published online February 1, 2016.
So far, the most commonly used thermodynamic model to describe the $\mathrm{N}$ solubility in molten steel is the Wagner interaction parameter formalism. ${ }^{[6]}$ But this model is limited only for specific alloy composition such as low carbon steel. The other model used in the commercial steel databases such as FactSage FSStel database $^{[7]}$ and Thermo-Calc TCFE database ${ }^{[8]}$ is the Bragg-Williams random mixing model with regular or subregular parameters. However, the available models and parameters are insufficient to reproduce the thermodynamic behavior of $\mathrm{N}$ in high alloy melts.

The purpose of this study is to develop a new thermodynamic database accurately describing the thermodynamic behavior of $\mathrm{N}$ in molten steel. In order to keep a pace with the development of high alloy steels, the database has been developed to describe entire composition range of liquid alloys in Fe-Al-Mn-Si-C system. In the present study, all the available experimental data related to the $\mathrm{N}$ solubility in unary, binary, ternary, and high order liquid were reviewed. Using the Modified Quasichemical Model with binary interaction model parameters between $\mathrm{N}$ and alloying elements, all available experimental data in ternary and higher order liquid systems were accurately predicted.

\section{THERMODYNAMIC MODEL}

\section{A. Limitations of Previous Thermodynamic Models}

\section{Wagner interaction parameter formalism}

The Wagner Interaction Parameter Formalism (WIPF) ${ }^{[6]}$ is the most common model used for the description of the thermodynamics of dilute solution. In order to overcome the thermodynamic inconsistency of this classical formalism and obey the Gibbs-Duhem relationship in non-dilute solution, Pelton and Bale ${ }^{[9,10]}$ introduced the Unified Interaction Parameter Formalism (UIPF) containing the correction term in the activity coefficient of solvent. For example, the molar Gibbs energy, $g$, of the Fe-M-N system ( $\mathrm{M}=$ alloying element such as $\mathrm{Al}, \mathrm{Mn}, \mathrm{Si}, \mathrm{C}$, and $\mathrm{N}=$ nitrogen) can be described by the UIPF as follows: 


$$
\begin{aligned}
g= & \left(X_{\mathrm{Fe}} g_{\mathrm{Fe}}^{\circ}+X_{\mathrm{M}} g_{\mathrm{M}}^{\circ}+X_{\mathrm{N}} g_{\mathrm{N}}^{\circ}\right) \\
& +R T\left(X_{\mathrm{Fe}} \ln X_{\mathrm{Fe}}+X_{\mathrm{M}} \ln X_{\mathrm{M}}+X_{\mathrm{N}} \ln X_{\mathrm{N}}\right) \\
& +R T\left(X_{\mathrm{Fe}} \ln \gamma_{\mathrm{Fe}}+X_{\mathrm{M}} \ln \gamma_{\mathrm{M}}+X_{\mathrm{N}} \ln \gamma_{\mathrm{N}}\right)
\end{aligned}
$$

where $g_{i}^{\circ}$ is the molar Gibbs energy of the $i$ element in the Raoultian standard state, $\gamma_{i}$ is the activity coefficients. When the standard states of $\mathrm{M}$ and $\mathrm{N}$ are changed to their infinite dilution standard states,

$$
\begin{aligned}
g= & \left(X_{\mathrm{Fe}} g_{\underline{\mathrm{Fe}}}^{\circ}+X_{\mathrm{M}} g_{\underline{\mathrm{M}}}^{\circ}+X_{\mathrm{N}} g_{\underline{\mathrm{N}}}^{\circ}\right) \\
& +R T\left(X_{\mathrm{Fe}} \ln X_{\mathrm{Fe}}+X_{\mathrm{M}} \ln X_{\mathrm{M}}+X_{\mathrm{N}} \ln X_{\mathrm{N}}\right) \\
& +R T\left(X_{\mathrm{Fe}} \ln f_{\underline{\mathrm{Fe}}}+X_{\mathrm{M}} \ln f_{\underline{\mathrm{M}}}+X_{\mathrm{N}} \ln f_{\underline{\mathrm{N}}}\right)
\end{aligned}
$$

where $g_{i}^{\circ}\left(=g_{i}^{\circ}+R T \ln \gamma_{i}^{\circ}\right)$ is the molar Gibbs energy of $i$ element in its infinite dilution (Henrian) standard state, and $f_{\underline{\mathrm{M}}}$ and $f_{\underline{\mathrm{N}}}$ are the activity coefficients relative to the infinite dilution standard state:

$$
\begin{array}{r}
\ln f_{\underline{\mathrm{M}}}=\sum_{i=\mathrm{M}, \mathrm{N}} \varepsilon_{\mathrm{Mi}} X_{i}+\sum_{i, j=\mathrm{M}, \mathrm{N}} \varepsilon_{\mathrm{M} i j} X_{i} X_{j}+\ln f_{\underline{\mathrm{Fe}}} \\
\ln f_{\underline{\mathrm{N}}}=\sum_{i=\mathrm{M}, \mathrm{N}} \varepsilon_{\mathrm{N} i} X_{i}+\sum_{i, j=\mathrm{M}, \mathrm{N}} \varepsilon_{\mathrm{N} i j} X_{i} X_{j}+\ln f_{\mathrm{Fe}} \\
\ln f_{\underline{\mathrm{Fe}}}=-\frac{1}{2} \sum_{i, j=\mathrm{M}, \mathrm{N}} \varepsilon_{i j} X_{i} X_{j}-\frac{2}{3} \sum_{i, j, k=\mathrm{M}, \mathrm{N}} \varepsilon_{i j k} X_{i} X_{j} X_{k}
\end{array}
$$

The $\ln f_{\mathrm{Fe}}$ term is the correction term in UIPF, which is set to be zero in the classical WIPF. Of course, the 1 wt pct standard state with $\mathrm{Fe}$ as a solvent can be also used, but then the validity of thermodynamic parameters (Henrian activity coefficients and interaction parameters) can be limited in Fe-rich solution rather than in wide range of solution.

Among the numerous studies, the compilations of the interaction parameters by Japanese Society for the Promotion of Science (JSPS) ${ }^{[1]}$ and Sigworth and Elliott $^{[12]}$ are the most well accepted one so far. However, this WIPF has two inherent limitations. The first limitation results from the assumption of ideal random entropy regardless of the interactions between solvent and solute and between solutes themselves. Although it may not be well-noticed in the calculations of activity or chemical reaction using interaction parameters, the overall Gibbs energy of solution expressed by the WIPF in Eqs. [1] or [2] clearly shows the ideal entropy of mixing. This is less realistic to describe the mixing entropy especially when there is highly negative interaction between species in solution. Typically, in the interaction parameter, $\varepsilon=A / T+B$, of WIPF, a large negative $A$ term (enthalpic term) requires a large $B$ term (entropic term). In order to overcome this limitation, Jung et al. ${ }^{[13]}$ introduced the Associate model for deoxidation equilibria. As the WIPF is originally designed for the description of dilute solution, there is no interpolation technique integrated in the Gibbs energy formalism. When the model is applied to non-dilute solution, there is always additional interaction terms required to correct the activity coefficients of solutes (in the end, the Gibbs energy of solution). Therefore, this model is unrealistic choice to describe liquid solution covering a wide range of composition.

\section{Bragg Williams random mixing model}

The Bragg Williams Random Mixing Model (BWRMM) is used for describing the Gibbs energy of liquid solution in a current commercial thermodynamic database like Thermo-Calc TCFE and FactSage FSStel. The Gibbs energy of solution Fe-M-N system can be expressed by the BWRMM as below:

$$
\begin{aligned}
g= & \left(X_{\mathrm{Fe}} g_{\mathrm{Fe}}^{\circ}+X_{\mathrm{M}} g_{\mathrm{M}}^{\circ}+X_{\mathrm{N}} g_{\mathrm{N}}^{\circ}\right) \\
& +R T\left(X_{\mathrm{Fe}} \ln X_{\mathrm{Fe}}+X_{\mathrm{M}} \ln X_{\mathrm{M}}+X_{\mathrm{N}} \ln X_{\mathrm{N}}\right) \\
& +\sum_{i, j}{ }^{m} L_{i j} X_{i} X_{j}\left(X_{j}-X_{i}\right)^{m}
\end{aligned}
$$

where ${ }^{m} L_{i j}$ are excess parameters between binary $i$ and $j$ species in solution ( $i$ and $j=\mathrm{Fe}, M$ and $\mathrm{N}$ ), which are expressed in the form of the Redlich-Kister polynomial. Due to the simplicity of the model equation, this has been widely used for the description of liquid alloy in the CALculation of PHAse Diagram (CALPHAD) method. The same model has been used by Miki and Hino for Fe-Ni-based alloy description. ${ }^{[14]}$ Like the WIPF, the random mixing entropy is also assumed in this model, and an intrinsic Muggianu interpolation technique ${ }^{[15]}$ is used to predict the Gibbs energy of ternary solution from binary excess model parameters, which are the limitations of the this model. As mentioned above, if the interaction between species is very negative, the entropy of solution would deviate from ideal entropy. In order to compensate this entropic limitation, large temperature-dependent parameters ${ }^{[13]} \mathrm{can}$ be often introduced which influence to non-configurational entropy of solution. In addition, the Muggianu interpolation technique is less satisfactory for the prediction of the Gibbs energy of dilute solution as pointed out by Pelton and Chartrand. ${ }^{[16]}$

\section{B. Modified Quasichemical Model: Present Study}

The Modified Quasichemical Model (MQM) $)^{[16,17]}$ in the pair approximation was used in order to take into account the short-range-ordering (SRO) exhibited in the Fe-Mn-Al-Si-C-N liquid solution. In comparison to the WIPF and BWRMM, the advantages of the MQM are (i) the intrinsic description of non-ideal mixing entropy of solution depending on the interaction of solution species and (ii) flexible choice of interpolation techniques for each ternary system. The detailed development of the MQM for binary ${ }^{[17]}$ and for multicomponent ${ }^{[16]}$ solutions can be found elsewhere. A brief description of the model will be presented here.

In the pair approximation of the MQM, the $A$ and $B$ atoms or molecules are assumed to be distributed on a quasi-lattice, and the following pair exchange reaction is considered: 


$$
(A-A)+(B-B)=2(A-B) ; \quad \Delta g_{A B}
$$

where $(i-j)$ represents the first-nearest neighbor (FNN) pair in metallic solution. The non-configurational Gibbs energy change for the formation of two moles of $(A-B)$ pairs is $\Delta g_{A B}$. Let $n_{A}$ and $n_{B}$ be the number of moles of $A$ and $B, n_{i j}$ be the number of moles of $(i-j)$ pairs, and $Z_{A}$ and $Z_{B}$ be the coordination numbers of $A$ and $B$. Then, the following mass balance equations for the pairs are obtained.

$$
\begin{aligned}
& Z_{A} n_{A}=2 n_{A A}+n_{A B} \\
& Z_{B} n_{B}=2 n_{B B}+n_{A B}
\end{aligned}
$$

The pair fractions, mole fractions, and "coordination-equivalent" fractions in the model are defined respectively as

$$
\begin{gathered}
X_{i j}=n_{i j} /\left(n_{A A}+n_{B B}+n_{A B}\right) \\
X_{A}=n_{A} /\left(n_{A}+n_{B}\right)=1-X_{B} \\
Y_{A}=Z_{A} n_{A} /\left(Z_{A} n_{A}+Z_{B} n_{B}\right) \\
=Z_{A} X_{A} /\left(Z_{A} X_{A}+Z_{B} X_{B}\right)=1-Y_{B}
\end{gathered}
$$

Then, the Gibbs energy of the $A-B$ binary solution is given by

$$
G=\left(n_{A} g_{A}^{\circ}+n_{B} g_{B}^{\circ}\right)-T \Delta S^{\text {config }}+\left(n_{A B} / 2\right) \Delta g_{A B}
$$

where $g_{A}^{\circ}$ and $g_{B}^{\circ}$ are the molar Gibbs energies of pure components of $A$ and $B$, and $\Delta S^{\text {config }}$ is an approximate expression for the configurational entropy of mixing given by randomly distributing the $(A-A)$, $(B-B)$, and $(A-B)$ pairs in the one-dimensional Ising approximation. ${ }^{[17]}$

$$
\begin{aligned}
& \Delta S^{\text {config }}=-R\left(n_{A} \ln X_{A}+n_{B} \ln X_{B}\right) \\
& -R\left[n_{A A} \ln \left(\frac{X_{A A}}{Y_{A}^{2}}\right)+n_{B B} \ln \left(\frac{X_{B B}}{Y_{B}^{2}}\right)+n_{A B} \ln \left(\frac{X_{A B}}{2 Y_{A} Y_{B}}\right)\right]
\end{aligned}
$$

$\Delta g_{A B}$ is expanded in terms of the pair fractions:

$$
\Delta g_{A B}=\Delta g_{A B}^{\circ}+\sum_{i \geq 1} g_{A B}^{i 0} X_{A A}^{i}+\sum_{j \geq 1} g_{A B}^{0 j} X_{B B}^{j}
$$

where $\Delta g_{A B}^{\circ}, g_{A B}^{i 0}$ and $g_{A B}^{0 j}$ are the parameters of the model which can be functions of temperature. When $\Delta g_{A B}=0$, the $\Delta S^{\text {config }}$ becomes ideal random entropy, while it becomes close to zero when $\Delta g_{A B} \ll 0$.

The composition of maximum SRO in each binary subsystem, typically corresponding to the composition of minimum enthalpy of mixing of binary solution, is determined by ratio of the coordination numbers, $Z_{B} / Z_{A}$, as given each of them by the following equations:

$$
\begin{aligned}
& \frac{1}{Z_{A}}=\frac{1}{Z_{A A}^{A}}\left(\frac{2 n_{A A}}{2 n_{A A}+n_{A B}}\right)+\frac{1}{Z_{A B}^{A}}\left(\frac{n_{A B}}{2 n_{A A}+n_{A B}}\right) \\
& \frac{1}{Z_{B}}=\frac{1}{Z_{B B}^{B}}\left(\frac{2 n_{B B}}{2 n_{B B}+n_{A B}}\right)+\frac{1}{Z_{B A}^{B}}\left(\frac{n_{A B}}{2 n_{B B}+n_{A B}}\right)
\end{aligned}
$$

where $Z_{A A}^{A}$ and $Z_{A B}^{A}$ are the values of $Z_{A}$, respectively, when all nearest neighbors of an $A$ are $A$ 's (that is, $Z$ for pure element $A$ ), and when all nearest neighbors of an $A$ are $B$ 's, and where $Z_{B B}^{B}$ and $Z_{B A}^{B}$ are defined similarly. $Z_{A B}^{A}$ and $Z_{B A}^{A}$ represent the same quantity and can be used interchangeably. The use of the one-dimensional Ising model in Eq. [14] introduces a mathematical approximation into the model which can be partially compensated by selecting smaller coordination numbers than the actual values. ${ }^{[18]}$ For the default coordination number, $Z_{i i}^{i}$, of pure element in metallic solution is set to be ' 6 ' in the FactSage metallic database. Then, binary coordination numbers, $Z_{i j}^{i}$, are used to fix the SRO composition. In the most cases, the default coordination number, ' 6 ', was applied in binary solutions in the present study. The expansion of the pair formation energies in each binary solution to the ternary and multicomponent system can be done considering the interpolation technique for each ternary system and the details of the formulation were described by Pelton and Chartrand. ${ }^{[16]}$

All binary MQM model parameters between metallic elements including $\mathrm{C}$ in liquid $\mathrm{Fe}-\mathrm{Al}-\mathrm{Mn}-\mathrm{Si}-\mathrm{C}$ solution were already optimized by the critical evaluation and optimization of all available phase diagram and thermodynamic properties data of liquid as well as solid phases. ${ }^{[19-27]}$ In the description of the Gibbs energy of liquid solution of Fe-Al-Mn-Si-C system, no ternary excess parameters were needed for liquid solution except for the Fe-Al-Mn solution. ${ }^{[27]}$ All these parameters were taken in the present study without any modification. The interpolation technique for each ternary system was determined based on the thermochemical properties of constituent sub-binary solutions. In the present study, all ternary systems containing nitrogen were treated by the Toop interpolation technique ${ }^{[28]}$ considering $\mathrm{N}$ as an asymmetric component.

\section{CRITICAL EVALUATION AND OPTIMIZATION OF $N$ SOLUBILITY IN BINARY AND TERNARY SYSTEMS}

All experimental data related to the solubility of $\mathrm{N}$ in the Fe-Al-Mn-Si-C were collected, and evaluated critically and simultaneously based on experimental technique and consistency with other set of experimental data to obtain the best model parameters to describe the binary $\mathrm{N}$ containing solutions. Then, the $\mathrm{N}$ solubilities in ternary and higher order liquid metal were predicted accurately without any additional model parameters. The Gibbs energies of all elements, Fe, Mn, Al, and Si in their liquid states were taken from the SGTE pure 


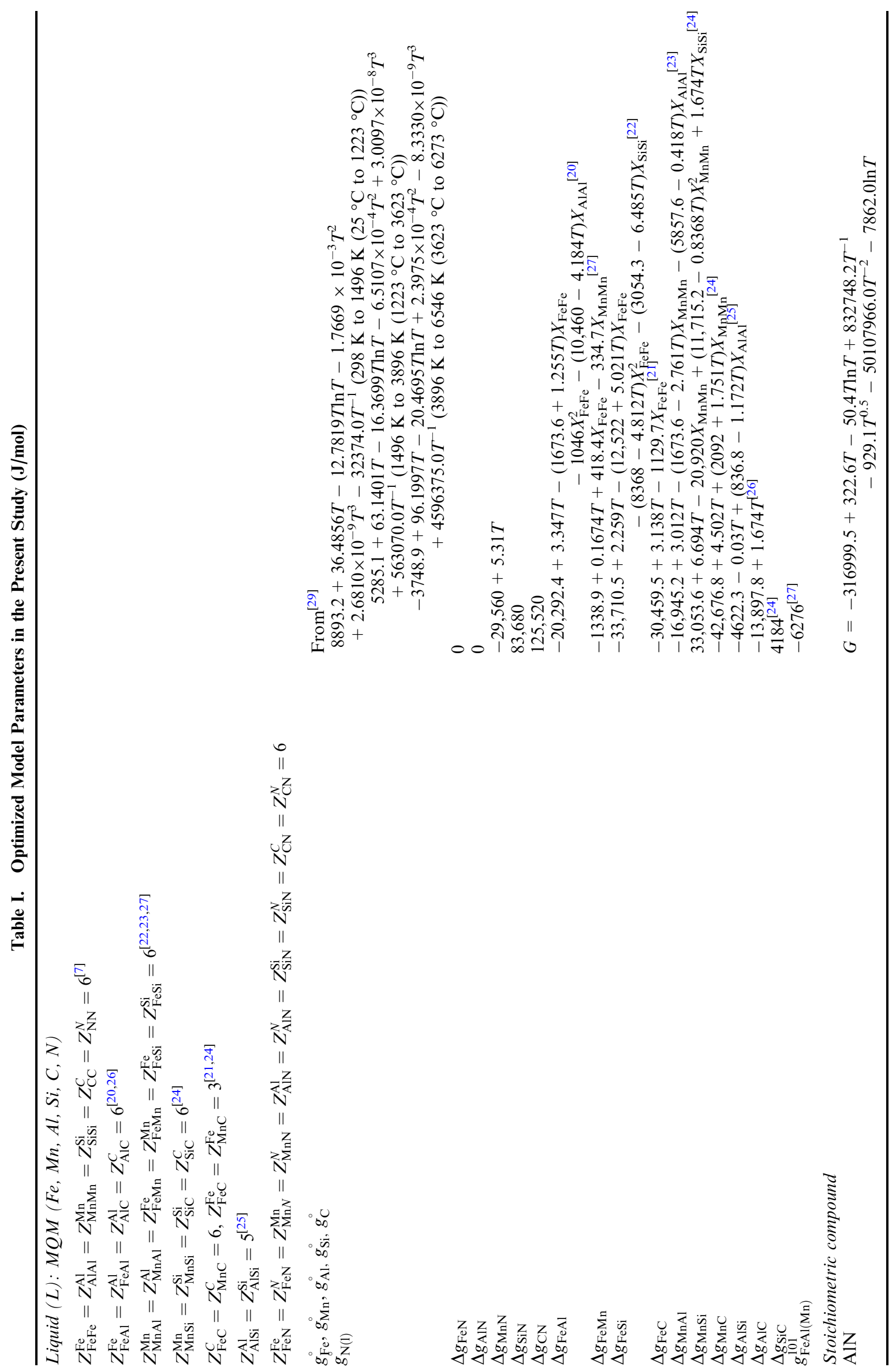


Table II. Interpolation Method for Each Ternary Liquid Systems Used in the Present Study

\begin{tabular}{lcll}
\hline System & Method* & $\begin{array}{c}\text { Asymmetric } \\
\text { Component }\end{array}$ & \multicolumn{1}{c}{ Refs. } \\
\hline Fe-Mn-Al & $\mathrm{T}$ & $\mathrm{Al}$ & 27 \\
Fe-Mn-Si & $\mathrm{M}$ & - & 7 \\
Fe-Mn-C & $\mathrm{T}$ & $\mathrm{C}$ & 19 \\
Fe-Mn-N & $\mathrm{T}$ & $\mathrm{N}$ & present study \\
Fe-Al-Si & $\mathrm{K}$ & - & 7 \\
Fe-Al-C & $\mathrm{T}$ & $\mathrm{Al}$ & 20 \\
Fe-Al-N & $\mathrm{T}$ & $\mathrm{N}$ & present study \\
Fe-Si-C & $\mathrm{T}$ & $\mathrm{Fe}$ & 19 \\
Fe-Si-N & $\mathrm{T}$ & $\mathrm{N}$ & present study \\
Fe-C-N & $\mathrm{T}$ & $\mathrm{N}$ & present study \\
Mn-Al-Si & $\mathrm{K}$ & - & 7 \\
Mn-Al-C & $\mathrm{T}$ & $\mathrm{Al}$ & 19 \\
Mn-Al-N & $\mathrm{T}$ & $\mathrm{N}$ & present study \\
Mn-Si-C & $\mathrm{T}$ & $\mathrm{Mn}$ & 24 \\
Mn-Si-N & $\mathrm{T}$ & $\mathrm{N}$ & present study \\
Mn-C-N & $\mathrm{T}$ & $\mathrm{N}$ & present study \\
Al-Si-C & $\mathrm{T}$ & $\mathrm{Al}$ & 19 \\
Al-Si-N & $\mathrm{T}$ & $\mathrm{N}$ & present study \\
Al-C-N & $\mathrm{T}$ & $\mathrm{N}$ & present study \\
Si-C-N & $\mathrm{T}$ & $\mathrm{N}$ & present study \\
\hline
\end{tabular}

*T, M, and $\mathrm{K}$ represent Toop, Muggianu, and Kohler interpolation technique, respectively.

substance database. ${ }^{[29]}$ Although solid carbon can be used as the reference state for conventional Wagner or Unified Interaction Parameter Formalism, liquid carbon Gibbs energy is required to describe liquid solution containing $\mathrm{C}$ for the MQM. Its Gibbs energy was originally evaluated by Gustafson ${ }^{[30]}$ to reproduce the phase diagram of $\mathrm{Fe}-\mathrm{C}$ system and activity of $\mathrm{C}$ in liquid $\mathrm{Fe}-\mathrm{C}$ solution. As liquid $\mathrm{N}$ does not exist as a stable elemental phase, it is impossible to measure the Gibbs energy of liquid N. In the course of this study, we found that the Gibbs energy of liquid $\mathrm{N}$ adopted in TCFE database and FSStel database could be unsatisfactory for the description of steel containing high amount of $\mathrm{N}$. Therefore, the Gibbs energy of liquid $\mathrm{N}$ was reevaluated, as described in Section III-A. All optimized model parameters determined in the present study are listed in Table I and the applied interpolation methods for each ternary system are listed in Table II.

\section{A. Re-assessment of the Gibbs Energy of Liquid Nitrogen}

The Gibbs free energy of pure liquid $\mathrm{N}, g_{\mathrm{N}(l)}^{\circ}$, is the one of the decisive factors to describe the Gibbs energy of liquid steel containing N. There is no definitive Gibbs energy of hypothetical liquid monoatomic $\mathrm{N}, \mathrm{N}(l)$. In the WIPF for dilute solution, the Henrian activity coefficient of $\mathrm{N}$ is determined after assuming $g_{\mathrm{N}(l)}^{\circ}=$ $1 / 2 g_{\mathrm{N}_{2}(g)}^{\circ}$ to describe the $\mathrm{N}$ solubility in pure liquid Fe. In the CALPHAD community, the Gibbs energy of $\mathrm{N}$ was determined to describe the phase diagram and other thermodynamic properties of $\mathrm{N}$-containing system in a wide range of composition and temperature. ${ }^{[31,32]}$ During the first thermodynamic assessment of the $\mathrm{Fe}-\mathrm{N}$ system, Frisk ${ }^{[31]}$ proposed the $g_{\mathrm{N}(l)}^{\circ}=1 / 2 g_{\mathrm{N}_{2}(g)}^{\circ}-711+$ $70.2 T$ to reproduce the phase diagram of the Fe-N system. Later, he realized that the original $g_{\mathrm{N}(l)}^{\circ}$ proposed for Fe-N system was not sufficient to describe other $\mathrm{N}$ containing systems such as $\mathrm{Cr}-\mathrm{N}$ and Mo-N system. So he revised the value as $g_{\mathrm{N}(l)}^{\circ}=1 / 2 g_{\mathrm{N}_{2}(g)}^{\circ}+$ $29950+59.02 T .^{[32]}$ In the both cases, he further added regular or sub-regular interaction parameters to describe the binary liquid solutions containing N. Although his thermodynamic descriptions of the binary systems are accurate enough under normal nitrogen pressures, certain potential problems were raised when the $\mathrm{N}_{2}$ gas phase is suppressed in the thermodynamic calculations during the evaluation of the data in the present study. For example, under suppression of nitrogen gas phase formation, FCC phase is calculated to reappear at high $\mathrm{N}$ content about 0.4 to $0.5 \mathrm{X}_{\mathrm{N}}$ below $743 \mathrm{~K}$ $\left(470{ }^{\circ} \mathrm{C}\right)$ in the Fe- $\mathrm{N}$ system and more critically $\mathrm{BCC}$ phase is stable again above the liquidus temperature in the $\mathrm{Cr}-\mathrm{N}$ systems (a wide range of $\mathrm{BCC}$ phase can be calculated above $2473 \mathrm{~K}\left(2200{ }^{\circ} \mathrm{C}\right)$ in the $\mathrm{Cr}-\mathrm{N}$ system $)$. The similar problem can be found in Mo-N system.

These problems result from the relative less stable Gibbs energy of liquid monoatomic $\mathrm{N}, g_{\mathrm{N}(l)}^{\circ}$. Therefore, we reassessed $g_{\mathrm{N}(l)}^{\circ}$ not only for the solubility of nitrogen gas in liquid alloy but also for the phase diagram calculations for all binary and high order systems containing $\mathrm{N}$. There are no definitive ways to determine the Gibbs energy of hypothetical liquid N. In this study, we determined the values of $g_{\mathrm{N}(l)}^{\circ}$ by assuming that the binary Fe-N liquid is an ideal solution. That is, the $g_{\mathrm{N}(l)}^{\circ}$ was adjusted to reproduce the solubility of nitrogen in the binary Fe-N liquid without any additional interaction parameters (strictly speaking, $\Delta g_{\mathrm{FeN}}=0$ in this study). Our preliminary tests for the optimizations of phase diagrams and thermodynamic properties of various binary $\mathrm{N}$ systems show no strange phase diagram results with this new $g_{\mathrm{N}(l)}^{\circ}=1 / 2 g_{\mathrm{N}_{2}(g)}^{\circ}+12643.9+45.939 T$.

\section{B. Evaluation and Optimization of Binary Systems}

The thermodynamic model parameters were determined based on the critically evaluated experimental data in the literature on the $\mathrm{N}$ solubility and AIN solubility product measured in liquid iron containing $\mathrm{Mn}, \mathrm{Al}, \mathrm{Si}, \mathrm{C}$, and $\mathrm{N}$. In general, the effects of alloying elements on the $\mathrm{N}$ solubility and the AlN formation in liquid iron have been measured by the Sieverts' method, levitation melting technique, and the sampling method. However, the Sieverts' method causes an error by the vaporization and condensation of metal as well as the side-chemical reactions. ${ }^{[33]}$ In case of levitation melting technique designed to eliminate the interaction between liquid solution and crucible materials, the presence of a film of metallic vapor near melt surface can cause an error in the temperature measurement by an optical pyrometer, and the equilibrium time is typically limited within 1 minute to avoid the evaporation of alloying 
elements at relatively higher operating temperature. ${ }^{[34]}$ With the sampling technique, the equilibrium $\mathrm{N}$ solubility can be underestimated by desorption of $\mathrm{N}$ (nitrogen gas formation) during quenching, ${ }^{[35]}$ but it was found that the quenching the samples in water within 3 seconds can be sufficient to keep original $\mathrm{N}$ content for most cases. ${ }^{[36}$ Recent sampling experiments under reduced partial pressures of $\mathrm{N}_{2}$ can especially reduce the chance of a loss of $\mathrm{N}$ during the quenching, which provides very reliable and consistent results. All these possible experimental and analytical advantage and disadvantage of each experimental technique were taken into account in the evaluation of the experimental data.

\section{1. $\mathrm{Fe}-\mathrm{N}$ system}

The experimental $\mathrm{N}$ solubilities in molten Fe at $1 \mathrm{~atm}$ $\mathrm{N}_{2}$ pressure are plotted in Figure 1. The $\mathrm{N}$ solubility in liquid iron has been measured by the Sieverts' method, ${ }^{[33,37,38]}$ the levitation melting technique, ${ }^{[39-42]}$ and the sampling method. ${ }^{[4-46]}$ The reported data of the $\mathrm{N}$ solubility are scattered significantly, and the temperature dependences of the data are different depending on the experimental studies. The $\mathrm{N}$ solubility in liquid $\mathrm{Fe}$ increases with increasing temperature. As both levitation technique and sampling method would induce a loss of nitrogen during experiments, the experimental data with higher $\mathrm{N}$ content were preferred among the reported data. Evaporation of liquid Fe can be expected at high temperature. As can be seen by the experimental data of Tsu and Saito, ${ }^{[41]}$ the $\mathrm{N}$ solubility decreases with temperature when experiment was carried out above $2473 \mathrm{~K}\left(2200^{\circ} \mathrm{C}\right)$. This can be well explained by the consideration of evaporation of $\mathrm{Fe}$, which induces the decrease of $\mathrm{N}_{2}$ pressure lower than $1 \mathrm{~atm}$ (due to dilution of $\mathrm{N}_{2}$ gas by $\mathrm{Fe}$ gas) as shown in calculated line (dashed line). Simultaneously, all experimental $\mathrm{data}^{[4,33,35,36,38,41,45-55]}$ at high and low partial pressure of $\mathrm{N}_{2}$ over a wide range of temperatures from $1823 \mathrm{~K}$ to $2173 \mathrm{~K}\left(1550{ }^{\circ} \mathrm{C}\right.$ to $\left.1900{ }^{\circ} \mathrm{C}\right)$, as shown in Figures $2(\mathrm{a})$ through (f), were considered in the evaluation of the

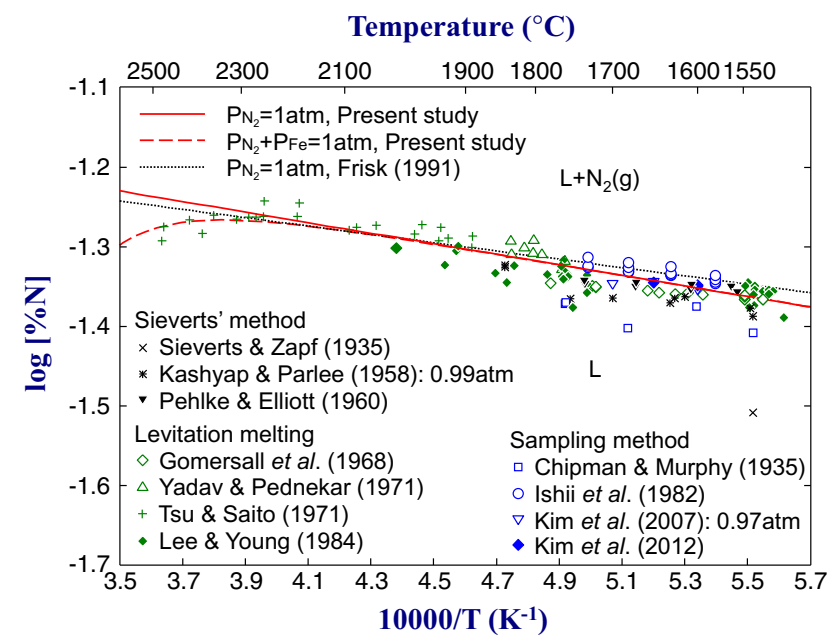

Fig. $1-\mathrm{N}$ solubility in liquid $\mathrm{Fe}$ at 1 atm $\mathrm{N}_{2}$ gas pressure ${ }^{[33,37-46]}$ along with the present optimization result and previous modeling result. ${ }^{[32]}$
Gibbs energy of liquid Fe-N solution. It should be noted that Firsk ${ }^{[31,32]}$ selected only the results of Ishii et al. ${ }^{[43]}$ among all other experimental data for his description of the Fe-N system without any supporting reason.

The maximum solubility of $\mathrm{N}$ in liquid $\mathrm{Fe}$ available among all experimental results is about $0.3 \mathrm{wt}$ pet $\mathrm{N}$ at $1873 \mathrm{~K} \quad\left(1600{ }^{\circ} \mathrm{C}\right)$ and $50 \mathrm{~atm} P_{\mathrm{N}_{2}}$ as shown in Figure 2(b). Up to this range of nitrogen concentration, the nitrogen solubility is increasing linearly with $P_{\mathrm{N}_{2}}^{1 / 2}$. That is, the $\mathrm{N}$ in liquid Fe shows the Henrian solution behavior at least up to this range of solubility. As mentioned in Section III-A, the $g_{\mathrm{N}(l)}^{\circ}$ value was determined to reproduce all $\mathrm{N}$ solubility data in liquid $\mathrm{Fe}$ without any MQM parameter, $\left(\Delta g_{\mathrm{FeN}}=0\right)$ :

$$
g_{\mathrm{N}(l)}^{\circ}=1 / 2 g_{\mathrm{N}_{2}(g)}^{\circ}+12643.9+45.939 T
$$

This means that the additional Gibbs energy term of $g_{\mathrm{N}(l)}^{\circ}$ in Eq. [18] can be mathematically considered as the Henrian activity coefficient of $\mathrm{N}$ in liquid $\mathrm{Fe}$ in the WIPF with no interaction parameters:

$$
R T \ln _{\mathrm{N}}^{\circ}=12643.9+45.939 T
$$

The Henrian activity coefficient derived from this study is very similar to the value suggested by the JSPS: ${ }^{[11]} R T \ln _{\mathrm{N}}^{\circ}=9916+46.954 T$.

\section{2. $M n-N$ system}

The Mn-N binary system was thermodynamically evaluated by Qui and Guillermet ${ }^{[56]}$ using the BWRMM for the liquid solution. By adopting the $g_{\mathrm{N}(l)}^{\circ}$ value evaluated by Frisk, ${ }^{[32]}$ they modeled the liquid solution using the subregular parameters (composition dependent). As shown in Figure 3, the $\mathrm{N}$ solubility calculated from their model parameters agrees well with the lower $\mathrm{N}$ solubility dataset. ${ }^{[57-61]}$ On the other hand, the higher $\mathrm{N}$ solubility dataset such as recent experimental data measured by Kim et al. ${ }^{[34]}$ at low temperature and Tsu and Saito ${ }^{[41]}$ at higher temperature region were more favored in the present optimization. As pointed out by Kim et al. ${ }^{[34]}$ and Tsu and Saito, ${ }^{[41]}$ the relatively high vapor pressure of $\mathrm{Mn}$ can affect the $\mathrm{N}_{2}$ partial pressure over the melt surface and the absorption of $\mathrm{N}$ by $\mathrm{Mn}$ vapor cannot be neglected in this system: The Mn vapor pressure is calculated to be 0.05 and 0.2 atm at $1873 \mathrm{~K}$ and $2073 \mathrm{~K}\left(1600{ }^{\circ} \mathrm{C}\right.$ and $\left.1800{ }^{\circ} \mathrm{C}\right)$, respectively. Kim et al. $^{[34]}$ and Tsu and Saito ${ }^{[41]}$ made corrections of the equilibrium $\mathrm{N}_{2}$ partial pressure by considering the $\mathrm{Mn}$ vapor pressure. The experimental data of Baratashvili et al. $^{[62]}$ are rather scattered. Although the equilibrium $\mathrm{N}$ solubility increases with decreasing temperature, the $\mathrm{N}$ pickup during the quenching of the sample cannot be expected due to slow dissolution kinetics of $\mathrm{N}$ into liquid metal. These data were well reproduced by introducing a small temperature-dependent $\Delta g_{\mathrm{MnN}}$ term (independent of composition), because the $\mathrm{N}$ dissolution shows the opposite temperature dependence with liquid Fe.

As mentioned in the Fe-N system, the evaporation of metallic element can affect the nitrogen partial pressure at high temperature. In particular, as $\mathrm{Mn}$ has much 


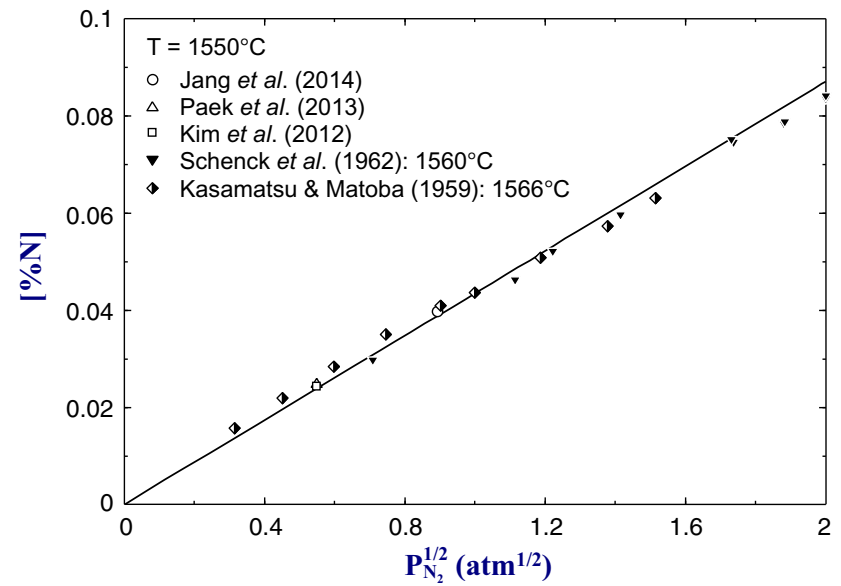

(a)

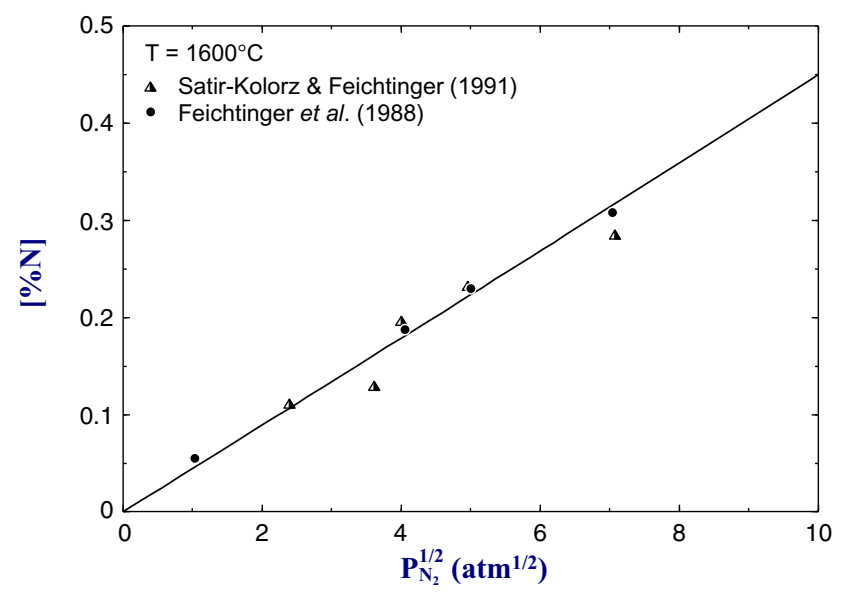

(b)

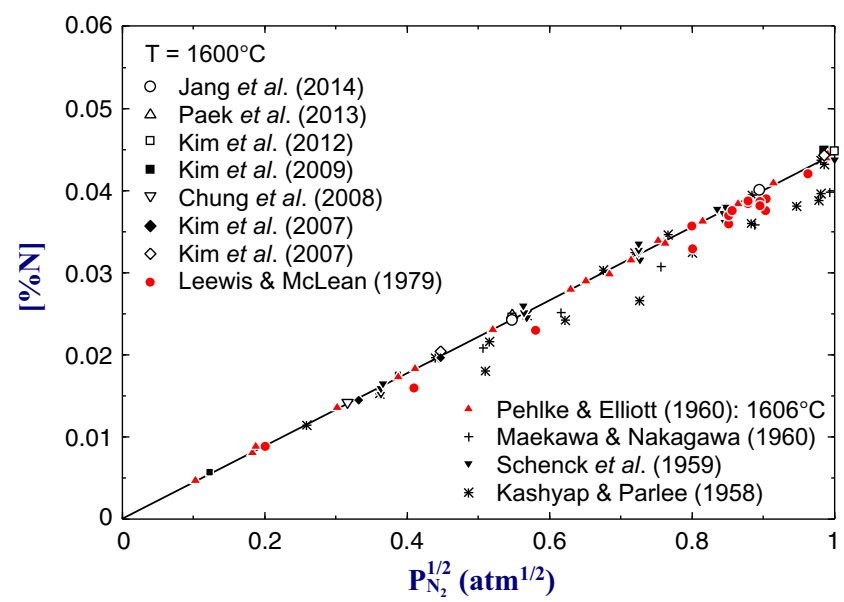

(c)

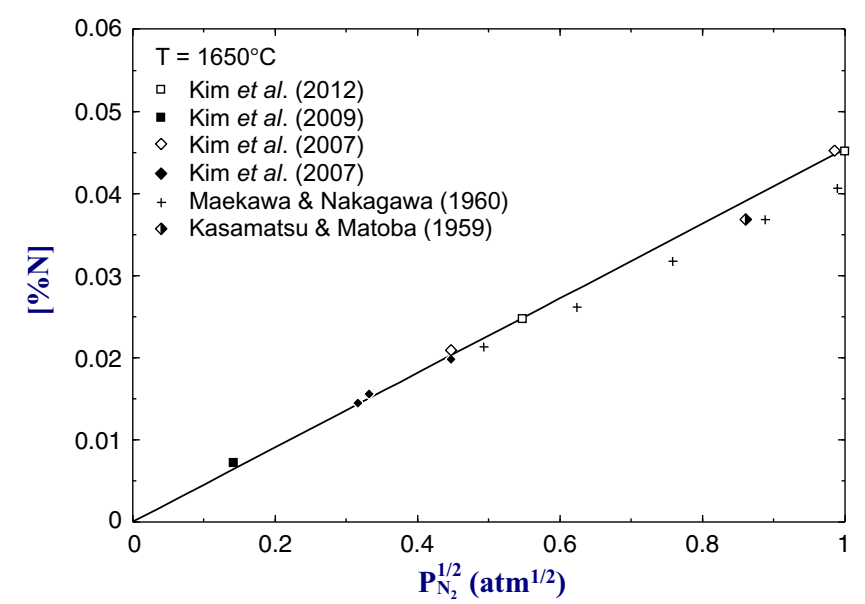

(d)

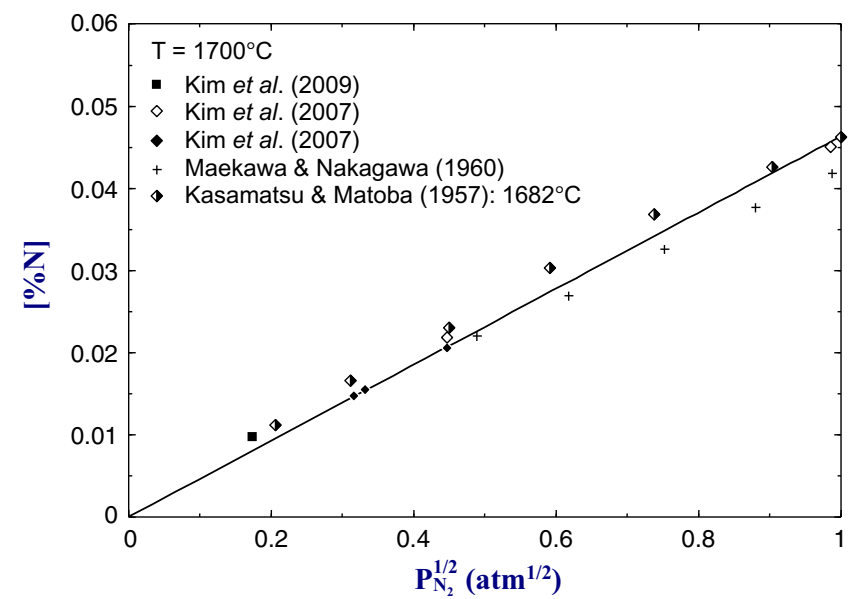

(e)

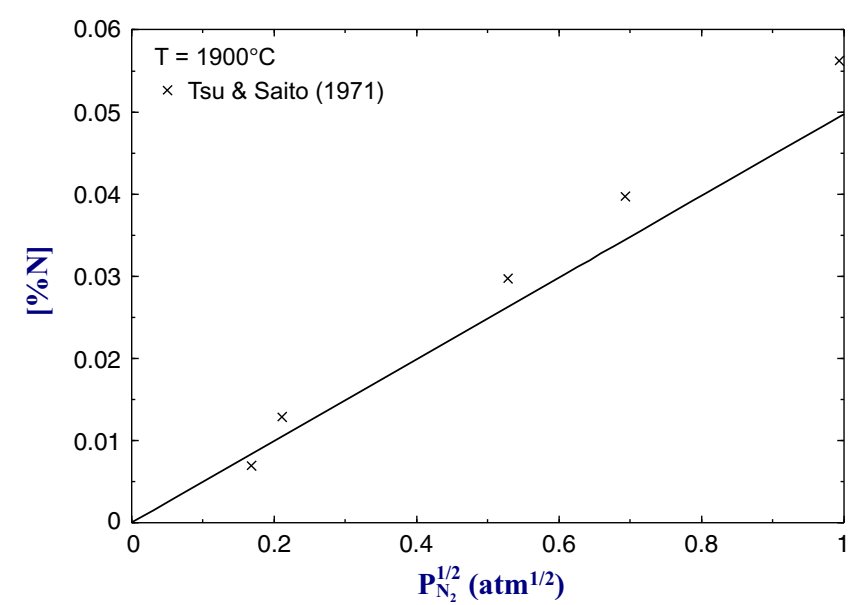

(f)

Fig. 2-Calculated $\mathrm{N}$ solubility in liquid Fe depending on the partial pressures of $\mathrm{N}_{2}$ along with experimental data. . $^{[4,33,35,36,38,41,45-55]}$

higher vapor pressure than $\mathrm{Fe}$, this should be taken into account in thermodynamic analysis. Dashed line in Figure 3 shows the calculated $\mathrm{N}$ solubility considering the $\mathrm{Mn}$ evaporation. In comparison to the calculated $\mathrm{N}$ solubility at $1 \mathrm{~atm} \mathrm{~N}_{2}$ pressure, the noticeable difference can be already found above $1873 \mathrm{~K}\left(1600{ }^{\circ} \mathrm{C}\right)$.
Figure 4 shows the effect of $\mathrm{N}_{2}$ partial pressure on the $\mathrm{N}$ solubility in liquid $\mathrm{Mn}$. The solubility of $\mathrm{N}$ in liquid $\mathrm{Mn}$ is much higher than that in liquid $\mathrm{Fe}$ at the same partial pressure of $\mathrm{N}_{2}$. As clearly shown in Figure 4, the $\mathrm{N}$ dissolution in liquid $\mathrm{Mn}$ does not follow the Sieverts' law. There are quite scatter in the experimental data in 


\section{Temperature $\left({ }^{\circ} \mathrm{C}\right)$}

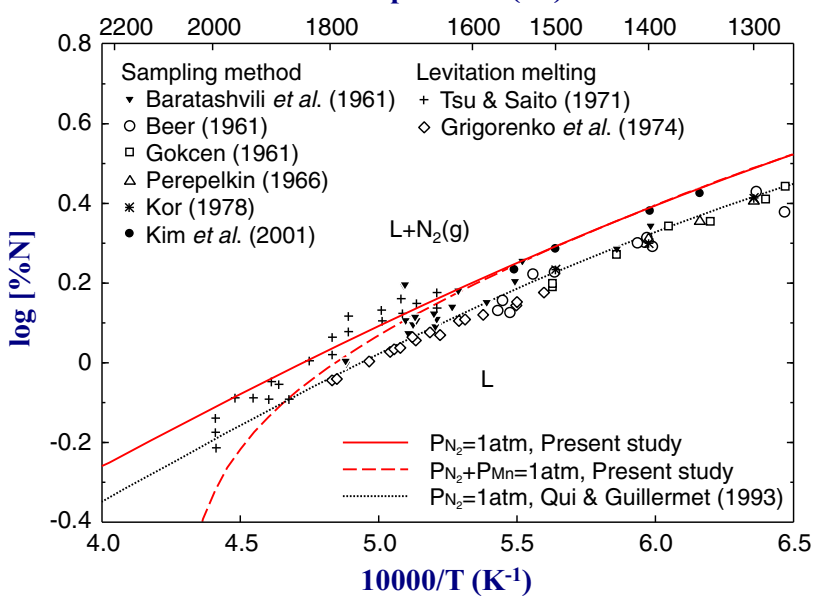

Fig. 3-N solubility in liquid $\mathrm{Mn}$ at $1 \mathrm{~atm} \mathrm{~N}_{2}$ pressure $^{[34,41,57-62]}$ along with the present optimization and previous modeling results. ${ }^{[56]}$

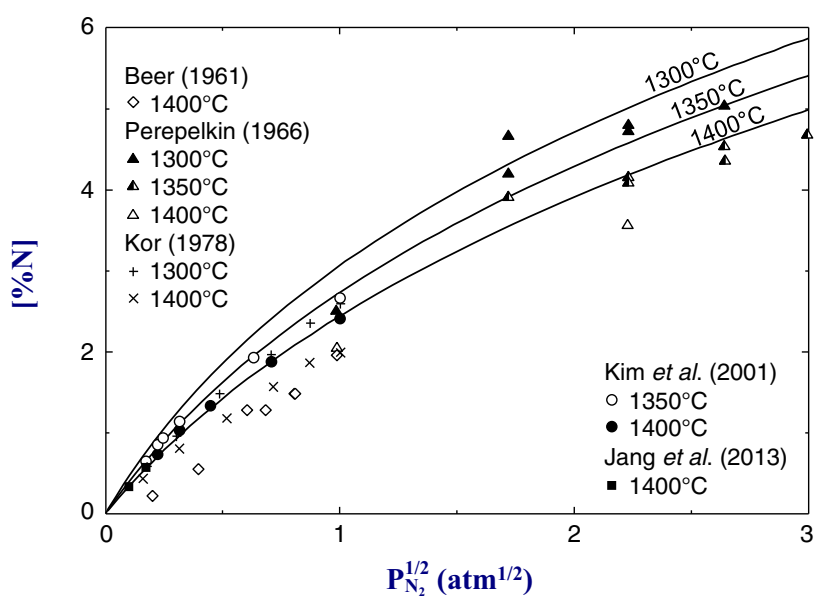

(a)

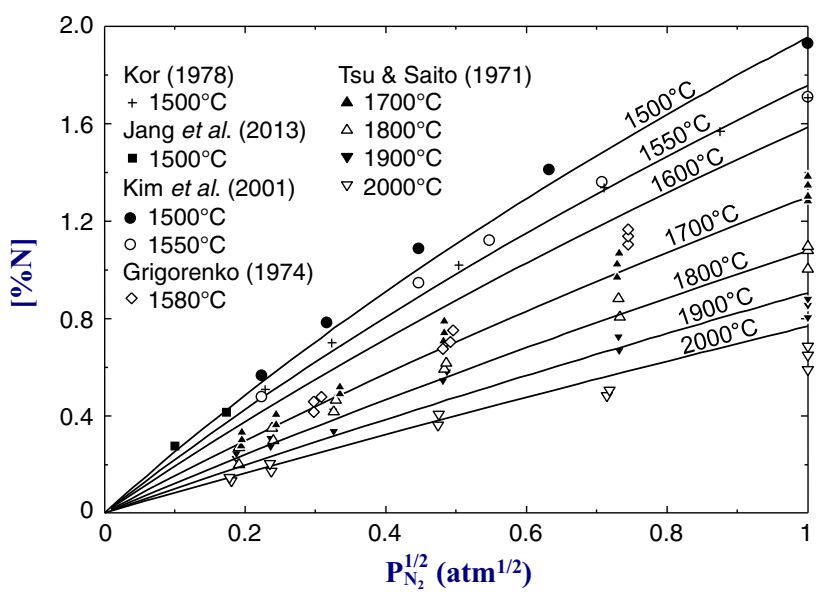

(b)

Fig. 4-Calculated N solubility in liquid Mn depending on the partial pressures of $\mathrm{N}_{2}$ along with experimental data. ${ }^{[34,41,57,59-61,63]}$

Figure 4, but present optimization agrees very well with the recent experimental results measured by Jang et $a .^{[63]}$ and Kim et al. ${ }^{[34]}$ at low temperature
(Figure 4(a)) and Tsu and Saito ${ }^{[41] \text { 's }}$ results at high temperature up to $2273 \mathrm{~K}\left(2000{ }^{\circ} \mathrm{C}\right)$ (Figure $\left.4(\mathrm{~b})\right)$. The results by Perepelkin ${ }^{[59]}$ which were measured under higher $\mathrm{N}_{2}$ partial pressures up to 9 atm were very scattered. The samples equilibrated under high pressures might lose significant amount of $\mathrm{N}$ during quenching if the pressure of $\mathrm{N}_{2}$ was not kept the same during the quenching.

\section{Al- $N$ system}

Several experimental studies ${ }^{[64-66]}$ are available on the $\mathrm{N}$ solubility in liquid $\mathrm{Al}$, and they are well reviewed by Wriedt. ${ }^{[67]}$ Figure 5 shows the experimental results of Iwase $^{[64]}$ and Schweighofer and Kúdela. ${ }^{[65,66]}$ Iwase $^{[64]}$ used the Sieverts' method in the temperature range from $973 \mathrm{~K}$ to $1203 \mathrm{~K}\left(700{ }^{\circ} \mathrm{C}\right.$ to $\left.930{ }^{\circ} \mathrm{C}\right)$. Schweighofer and Kúdela $^{[65,66]}$ analyzed the amount of AlN in the quenched Al samples after equilibrating liquid Al with $\mathrm{N}_{2}$ gas of 20 to $50 \mathrm{~atm}$ using an induction melting apparatus, and then they calculated the $\mathrm{N}$ solubility under $1 \mathrm{~atm} \mathrm{~N}_{2}$ pressure using the Sieverts' law with the assumption that analyzed AIN in quenched sample was all soluble $\mathrm{N}$ state in liquid $\mathrm{Al}$. In both studies, they could not find any detectable soluble $\mathrm{N}$ in $\mathrm{Al}$ and assumed that all AlN in Al was originally soluble $\mathrm{N}$. Theoretically, AIN is very stable so it should be formed under their experimental conditions. For example, as pointed out by Wriedt ${ }^{[67]}$, the equilibrium $\mathrm{N}_{2}$ gas pressure for 'liquid $\mathrm{Al}+\mathrm{AlN}$ ' assemblage at about $1273 \mathrm{~K}\left(1000{ }^{\circ} \mathrm{C}\right)$ is about $10^{-16}$ atm and the equilibrium amount of $\mathrm{N}$ in liquid $\mathrm{Al}$ should be less than ppm level, which is not detectable using common analytical tools. Although Iwase ${ }^{[64]}$ and Schweighofer and Kúdela $^{[65,66]}$ claimed that the formation of A1N was very sluggish so they could effectively reach the metastable equilibration between $\mathrm{Al}$ and $\mathrm{N}_{2}$ gas, their results are doubtable. Several other experimental studies $^{[68,69]}$ reported nearly no solubility of $\mathrm{N}$ in liquid $\mathrm{Al}$ up to $1773 \mathrm{~K}\left(1500{ }^{\circ} \mathrm{C}\right)$. In particular, Czochralsk ${ }^{[68]}$ and Claus ${ }^{[69]}$ used the Sieverts' method but they reported no detectable $\mathrm{N}$ in liquid $\mathrm{Al}$, which cast the doubt about the Iwase's results.

In the present study, the MQM parameter for Al-N was set to be zero: $\Delta g_{\mathrm{AlN}}=0$. In order to compare the metastable nitrogen dissolution into liquid Al claimed by Iwase ${ }^{[64]}$ and Schweighofer and Kúdela, ${ }^{[65,66]}$ we calculated the metastable equilibration between liquid $\mathrm{Al}$ and $1 \mathrm{~atm} \mathrm{~N}_{2}$ gas with suppression of AlN formation. As can be seen in Figure 5, the calculated solubility from the present model is about twice higher than the experimental data by Iwase and Schweighofer and Kúdela. In order to reproduce these experimental data, a temperature-independent negative parameter of $\Delta g_{\mathrm{AIN}}$ would be necessary. It should be noted that the calculated results and experimental data in Figure 5 are metastable and in reality stable solid A1N should form during the dissolution of $\mathrm{N}$ in liquid $\mathrm{Al}$ under equilibrium condition. In the course of the thermodynamic modeling of the ternary Fe-Al-N solution, it was found that zero $\Delta g_{\text {AIN }}$ parameter is more suitable to predict the nitrogen solubility in Fe-Al melt (see in Section III-C-2). Therefore, considering that the 


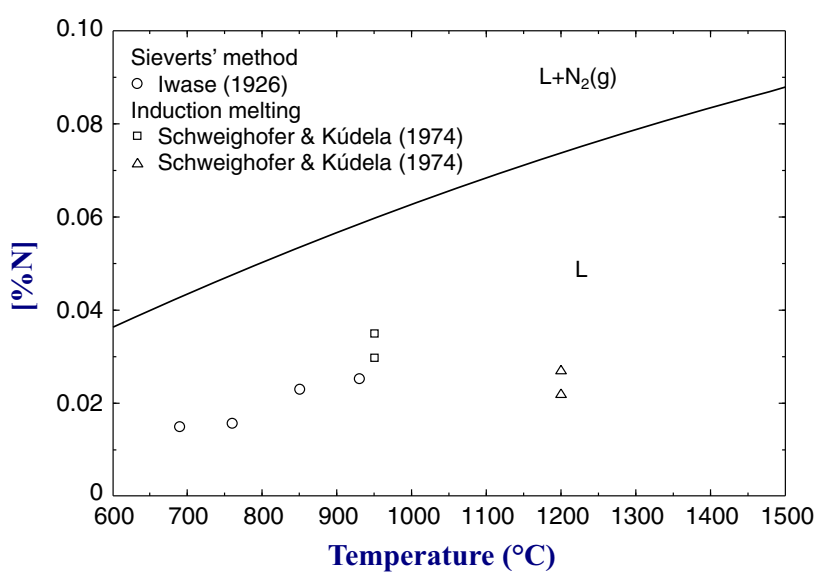

Fig. 5-Solubility of $\mathrm{N}$ in liquid $\mathrm{Al}$ under $1 \mathrm{~atm}$ pressure: metastable equilibrium assuming no AIN formation (see text for more explanation).

experimental results by Iwase $^{[64]}$ and Schweighofer and Kúdela ${ }^{[65,66]}$ in Figure 5 were obtained in metastable condition, it was decided to keep the $\Delta g_{\text {AIN }}=0$ for more accurate predictions in higher order system.

\section{Si-N and $C-N$ systems}

No solubility of $\mathrm{N}$ in liquid $\mathrm{Si}$ has been determined experimentally. Due to high melting temperature of $\mathrm{C}$, no experiments for the solubility of $\mathrm{N}$ in liquid $\mathrm{C}$ have been attempted. The temperature for the three phase equilibria of 'liquid $\mathrm{Si}+$ solid $\mathrm{Si}_{3} \mathrm{~N}_{4}+$ gas $\mathrm{N}_{2}$ (1 atm)' was predicted as part of evaluation of the Gibbs energy of $\mathrm{Si}_{3} \mathrm{~N}_{4},{ }^{[70]}$ but the predicted solubility of nitrogen in liquid $\mathrm{Si}, 723$ wt ppm $\mathrm{N}$ at $2150 \mathrm{~K}\left(1877^{\circ} \mathrm{C}\right)$, in this condition is not supported by any experimental results. Therefore, the model parameter for each system, $\Delta g_{\mathrm{SiN}}$ and $\Delta g_{\mathrm{CN}}$, cannot be determined from the binary systems. In the present study, they were determined to reproduce the experimental data for ternary $\mathrm{Fe}-\mathrm{Si}-\mathrm{N}$ and $\mathrm{Fe}-\mathrm{C}-\mathrm{N}$ systems, as will be discussed in Sections III-C -3 and III-C -4 . The calculated solubilities of nitrogen in liquid $\mathrm{Si}$ at $1773 \mathrm{~K}\left(1500{ }^{\circ} \mathrm{C}\right)$ and $1873 \mathrm{~K}$ $\left(1600{ }^{\circ} \mathrm{C}\right)$ from the present model parameters are 0.034 , and $0.088 \mathrm{wt} \mathrm{ppb}$, respectively. In the case of the three phase equilibration of 'liquid $\mathrm{Si}+$ solid $\mathrm{Si}_{3} \mathrm{~N}_{4}+$ gas $\mathrm{N}_{2}$ ( $1 \mathrm{~atm})^{\prime}$, the solubility is $0.75 \mathrm{wt} \mathrm{ppb}$ at $2144 \mathrm{~K}$ $\left(1871{ }^{\circ} \mathrm{C}\right)$.

\section{Evaluation and Optimization of Ternary Systems}

All the experimental data in ternary alloy melts were well predicted from the MQM using only binary model parameters with the Toop interpolation technique where $\mathrm{N}$ was considered as an asymmetric component.

\section{Fe-Mn-N system}

The $\mathrm{N}$ solubilities in liquid Fe-Mn alloy have been measured over wide composition and temperature ranges under various $\mathrm{N}_{2}$ partial pressures. Figure 6

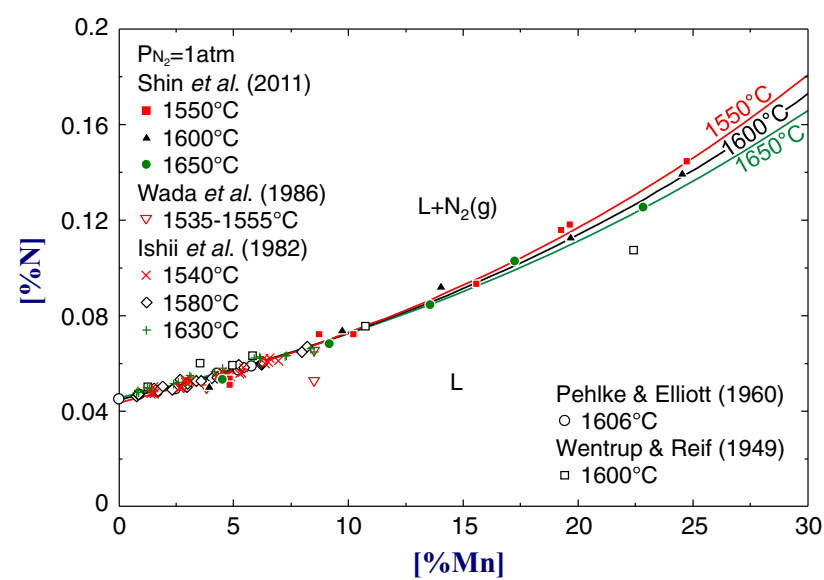

(a)

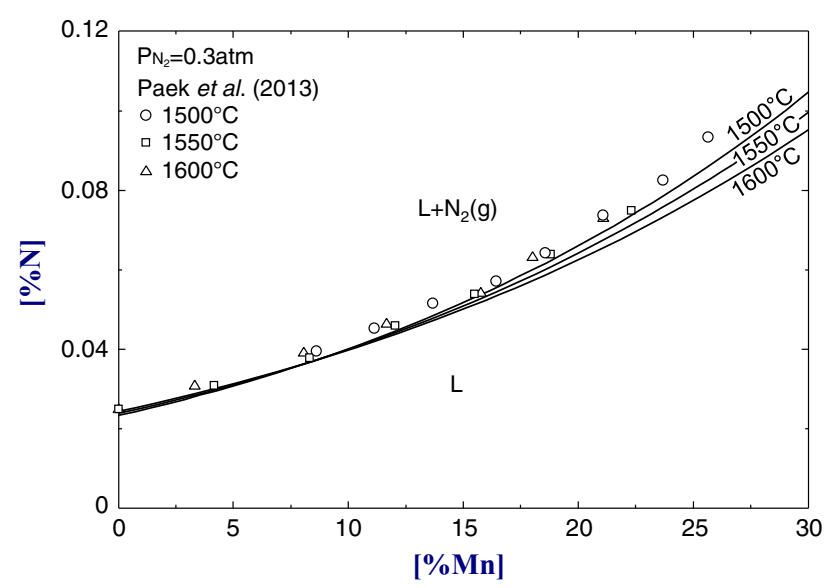

(b)

Fig. 6 - Comparison between experiments ${ }^{[4,33,71-74]}$ and model calculations for $\mathrm{N}$ solubility in $\mathrm{Fe}-\mathrm{Mn}$ melts at Fe-rich region under the $\mathrm{N}_{2}$ partial pressure of $(a) 1$ and $(b) 0.3 \mathrm{~atm}$.

shows the $\mathrm{N}$ solubility in liquid Fe-Mn alloys measured by various investigators ${ }^{[4,33,71-74]}$ at the temperatures from about $1823 \mathrm{~K}$ to $1923 \mathrm{~K}\left(1550{ }^{\circ} \mathrm{C}\right.$ to $\left.1650{ }^{\circ} \mathrm{C}\right)$ under (a) 1 and (b) $0.3 \mathrm{~atm} \mathrm{~N}_{2}$ partial pressures. As shown in the figure, the $\mathrm{N}$ solubility significantly increases with increasing $\mathrm{Mn}$ content. The temperature dependence of the solubility changes from positive to negative at about $8.5 \mathrm{wt}$ pct of $\mathrm{Mn}$ in this temperature range. Shin et al. ${ }^{[71]}$ 's results measured by $\mathrm{N}_{2}$ bubbling and sampling method clearly showed the effect of $\mathrm{Mn}$ on the $\mathrm{N}$ solubility in liquid iron and its temperature dependence. The predicted $\mathrm{N}$ solubility from the present model is compared to more experimental data in Figure 7. As discussed in binary $\mathrm{Mn}-\mathrm{N}$ system (see Section III-B-2), many previous experimental data on the $\mathrm{N}$ solubility in liquid $\mathrm{Mn}$ are lower than the calculated solubility from the present optimization, but the present modeling was based on the more recent experimental data and the data including the correction of Mn partial pressure. As can be seen in Figure 7(a), the recent measurements by Jang et al..$^{[75]}$ up to 55 wt pct of $\mathrm{Mn}$ and by Kim et al. ${ }^{[34]}$ from 75 to 100 wt pet $\mathrm{Mn}$ at $\mathrm{N}_{2}$ partial pressure of $0.2 \mathrm{~atm}$ are well predicted, while the other experimental results in 


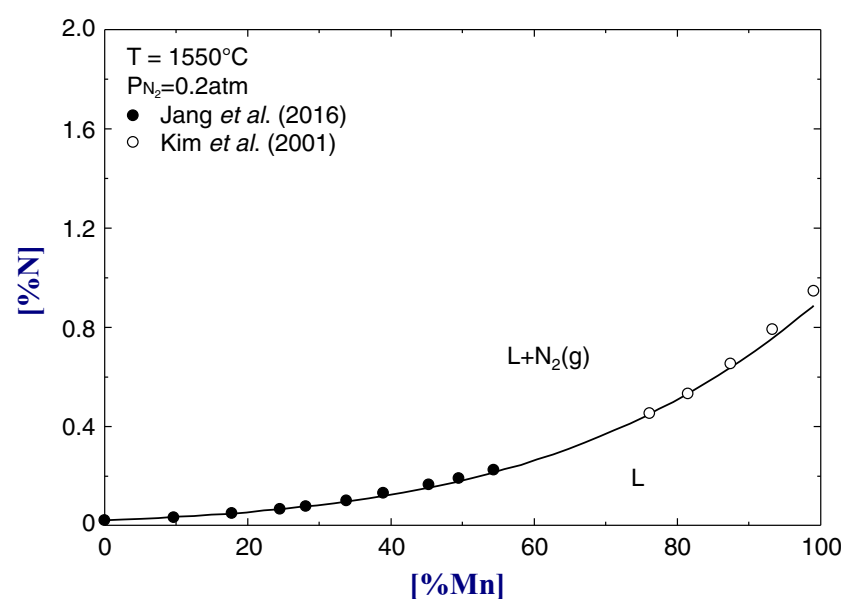

(a)

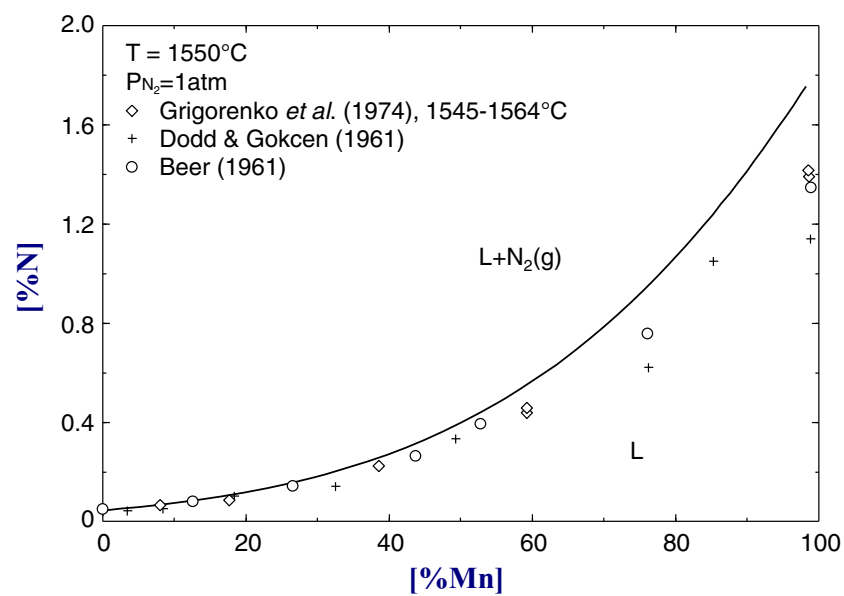

(b)

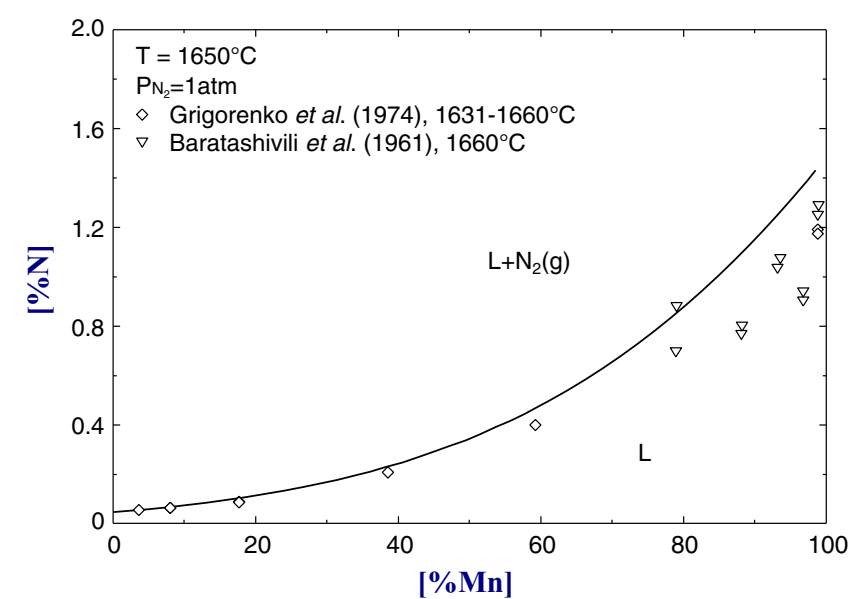

(c)

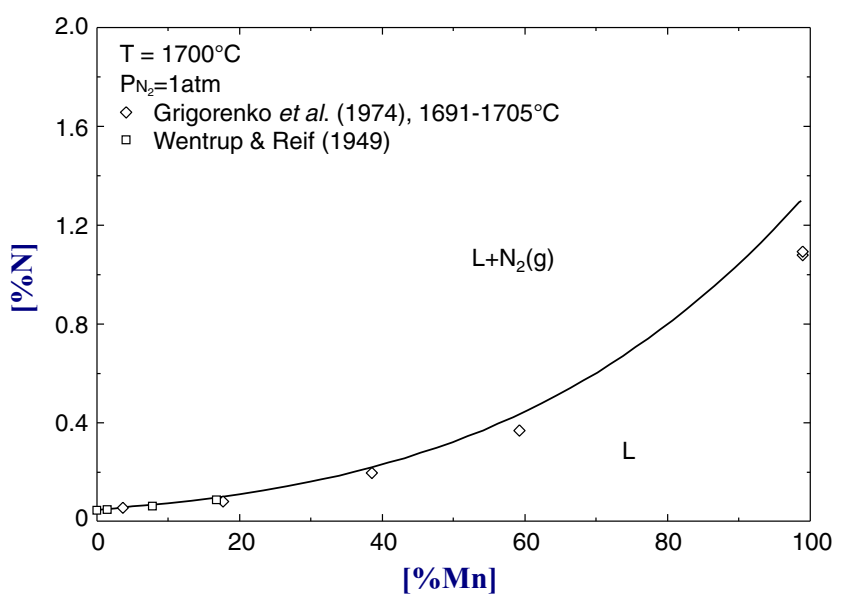

(d)

Fig. 7-Comparison between experiments ${ }^{[34,57,61,74-77]}$ and model calculations for $\mathrm{N}$ solubility in Fe-Mn melts at $1823 \mathrm{~K}\left(1550{ }^{\circ} \mathrm{C}\right)$ under $(a)$ $0.2 \mathrm{~atm}$, and at $(b) 1823 \mathrm{~K}\left(1550^{\circ} \mathrm{C}\right),(c) 1923 \mathrm{~K}\left(1650^{\circ} \mathrm{C}\right)$, and $(d) 1973 \mathrm{~K}\left(1700^{\circ} \mathrm{C}\right)$ under $1 \mathrm{~atm} \mathrm{~N}_{2}$ pressure.

Figures 7(b) through (d) under 1 atm $\mathrm{N}_{2}$ pressure ${ }^{[57,61,74,76,77]}$ show systemically lower than the predictions particularly at high $\mathrm{Mn}$ concentration region. This could result from the interference of high vapor pressure of $\mathrm{Mn}$ to partial pressure of $\mathrm{N}_{2}$, and also a loss of $\mathrm{N}$ during the quenching/cooling of samples when $\mathrm{N}_{2}$ gas pressure was not kept isobaric.

Grigorenko et al. ${ }^{[61]}$ and Beer ${ }^{[57]}$ determined the solubility of $\mathrm{N}$ with the variation of partial pressure of $\mathrm{N}_{2}$. As shown in Figures 8(a) and (b), the $\mathrm{N}$ solubility is well predicted at low partial pressure of $\mathrm{N}_{2}$ but the deviation becomes noticeable at high $\mathrm{N}_{2}$ pressures and high $\mathrm{Mn}$ concentration region. The similar trend can be found for the experimental results from Satir-Kolorz and Fechtinger ${ }^{[50]}$ and Rawers and Gokcen ${ }^{[78]}$ under higher $\mathrm{N}_{2}$ pressures up to 99 and 1974 atm, respectively, as shown in Figures 8(c) and (d). The calculated results are consistently higher than the experimental results. This discrepancy can be due to the loss of nitrogen during the quenching of the samples.

2. $\mathrm{Fe}-\mathrm{Al}-\mathrm{N}$ system

This system has been extensively investigated experimentally ${ }^{[5,33,45,46,73,79-83]}$ and theoretically ${ }^{[4,85]}$.
However, there are still disagreements among the studies. In particular, there are considerable discrepancies in the Gibbs energy of formation of AlN. ${ }^{[45,80,81,84-86]}$ The effect of $\mathrm{Al}$ on the activity coefficient of $\mathrm{N}$ in liquid iron recommended by the JSPS $^{[11]}$ is positive whereas that by the previous CALPHAD-type optimizations is negative. ${ }^{[84,85]}$ This can cause significant difference in the prediction of the solubility of $\mathrm{N}$ and the formation of $\mathrm{AlN}$ in liquid $\mathrm{Fe}$ containing a large amount of $\mathrm{Al}$.

The standard Gibbs energy of formation of AlN from $\mathrm{Al}(\mathrm{l})$ and $1 / 2 \mathrm{~N}_{2}(\mathrm{~g})$ was determined from the sublimation behavior of AlN ${ }^{87-89]}$ and the carbothermal nitridation method. ${ }^{[90]}$ The standard Gibbs energy data of AIN derived from the experiments are plotted in Figure 9. By adopting the sublimation coefficient value from Hildenbrand and Hall, ${ }^{[87]}$ we calculated the Gibbs energies of formation of AlN from the experimental sublimation studies by Bolgar et al. ${ }^{[88]}$ and Dreger et al. ${ }^{[89]}$ As can be seen in Figure 9, the experimental data are very scattered.

The Gibbs free energy of AlN in the JANAF tables ${ }^{[86]}$ was determined mainly based on the results of Hildenbrand and Hall. ${ }^{[87]}$ However, it was found that the 


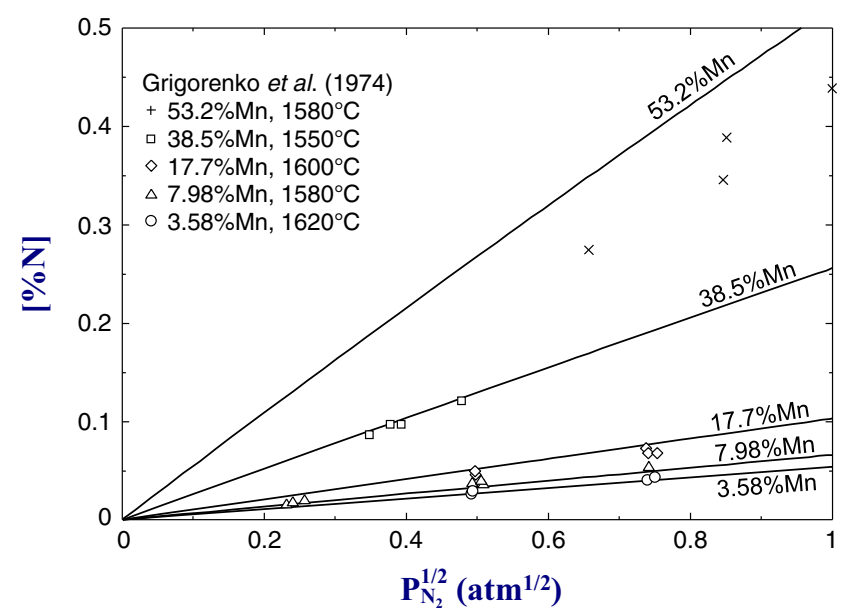

(a)

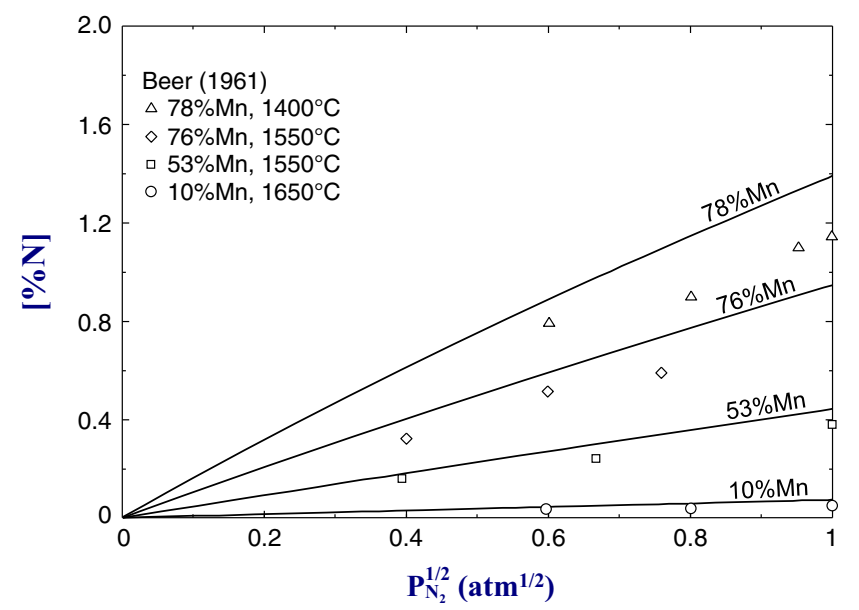

(b)

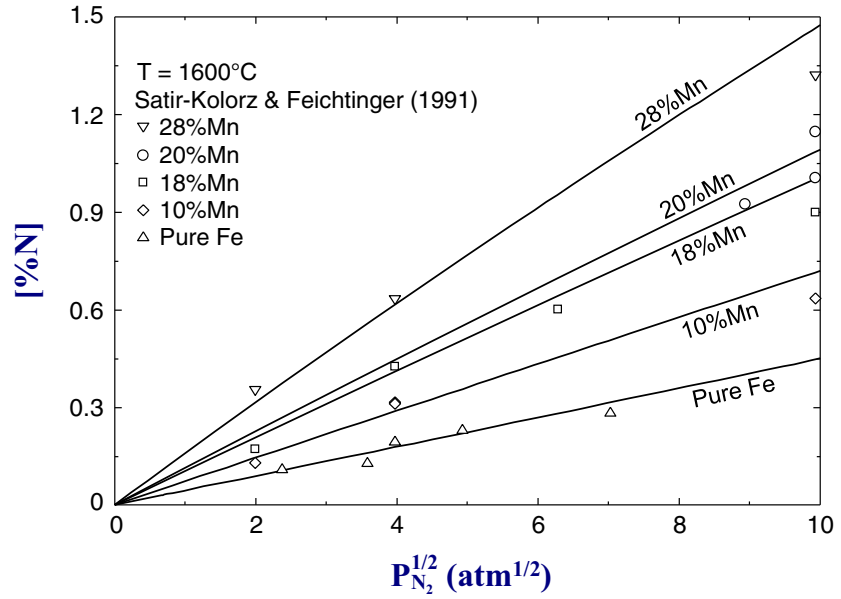

(c)

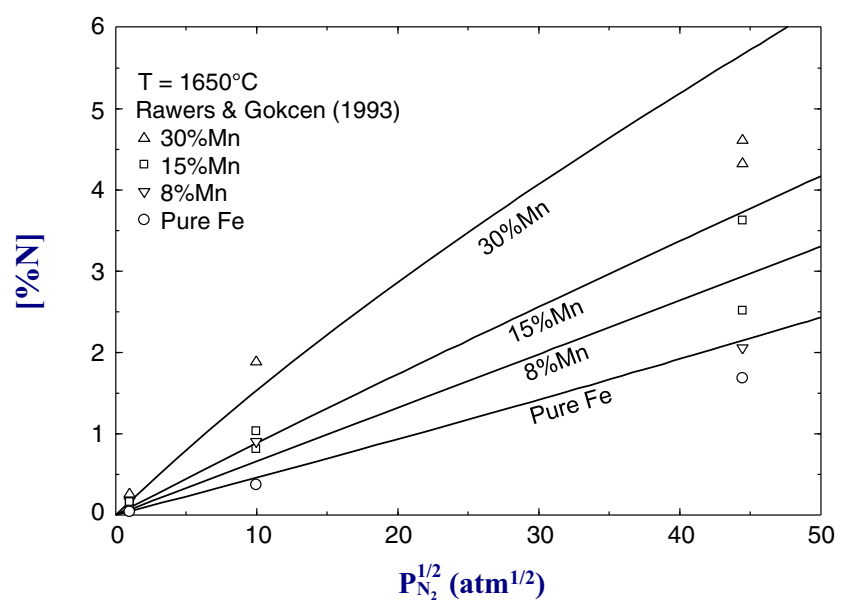

(d)

Fig. 8 - Calculated $\mathrm{N}$ solubility in liquid Fe-Mn alloys depending on the partial pressure of $\mathrm{N}_{2}$ along with experimental results from (a) Grigorenko et al.,${ }^{[61]}(b)$ Beer, ${ }^{[57]}(c)$ Satir-Kolorz and Feichtinger, ${ }^{[50]}$ and $(d)$ Rawers and Gokcen. ${ }^{[78]}$

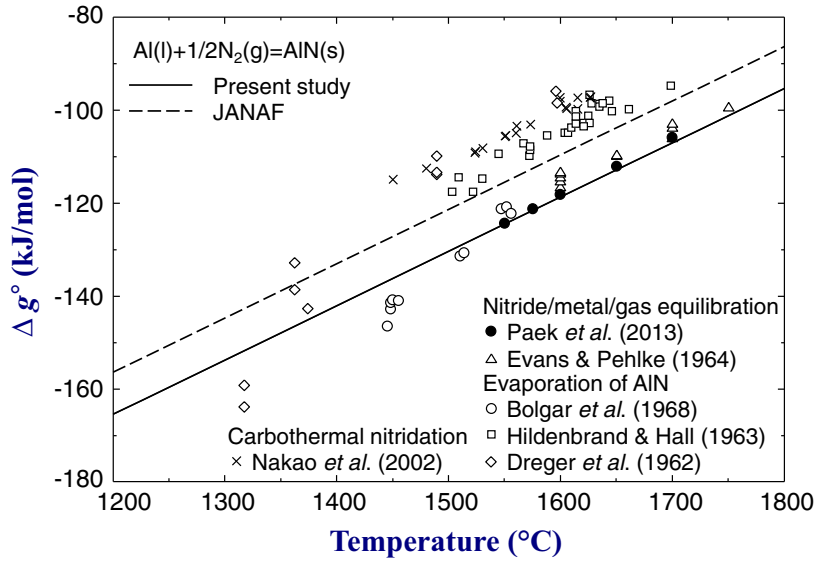

Fig. 9-Standard Gibbs free energy of formation of $\mathrm{AlN}^{[81,87-91]}$ from liquid $\mathrm{Al}$ and $\mathrm{N}_{2}$ gas.

Gibbs free energy from JANAF tables was rather positive to reproduce the AlN solubility product data in liquid iron..$^{[5,45,46,73,79-82]}$ For example, the Gibbs energy of formation of AlN was calculated from AlN solubility product data by Paek et al. ${ }^{[91]}$ and Evans and Pehlke ${ }^{[81]}$ using the activity coefficient of $\mathrm{Al}$ and $\mathrm{N}$ in this study, and plotted in Figure 9. The standard enthalpy of formation of AlN from $\mathrm{Al}(\mathrm{l})$ and $1 / 2 \mathrm{~N}_{2}(\mathrm{~g})$ was determined by the direct nitridation $(-320.0 \pm$ $0.8 \mathrm{~kJ} / \mathrm{mol})^{[92]}$ and the combustion calorimetry $(-316.3$ $\pm 1.7 \mathrm{~kJ} / \mathrm{mol}){ }^{[93]}$ The enthalpy can be also indirectly determined from the Gibbs energy plotted in Figure 9 by assuming the linear temperature dependence of the standard Gibbs energy of formation: -312.9 to $-329.7 \mathrm{~kJ} / \mathrm{mol}$ from the AlN sublimation experiments, ${ }^{[87-89]}$ and $-308.2 \mathrm{~kJ} / \mathrm{mol}$ from the carbothermal nitridation method. ${ }^{[90]}$ In order to reproduce the AIN solubility data in liquid $\mathrm{Fe}$, in the present study, the standard entropy of formation and heat capacity of AlN were taken from the JANAF tables and then standard enthalpy of formation of AIN of the JANAF tables was modified from -318.0 to $-327.0 \mathrm{~kJ} / \mathrm{mol}$.

Figure 10 shows the calculated phase diagrams of the Fe-Al-N system at various temperatures under different partial pressures of $\mathrm{N}_{2}$. All available experimental data 


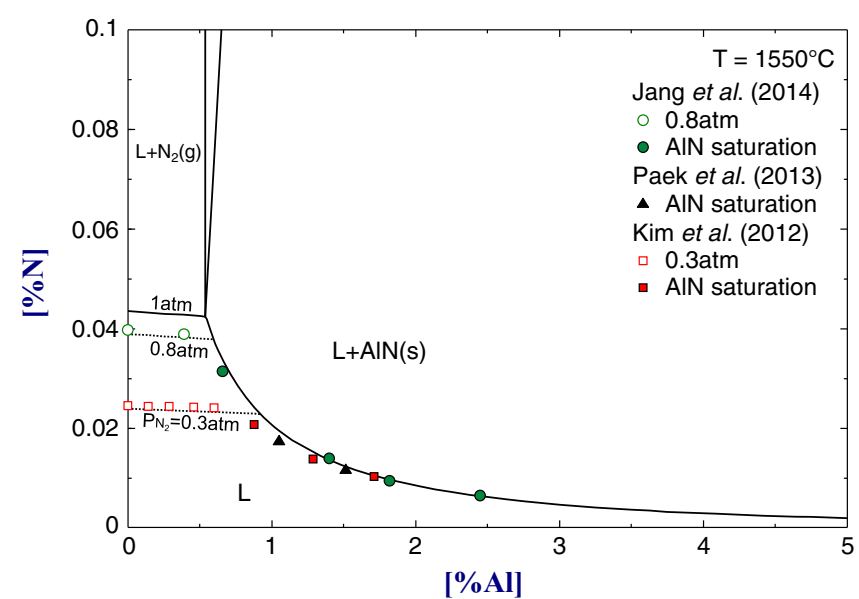

(a)

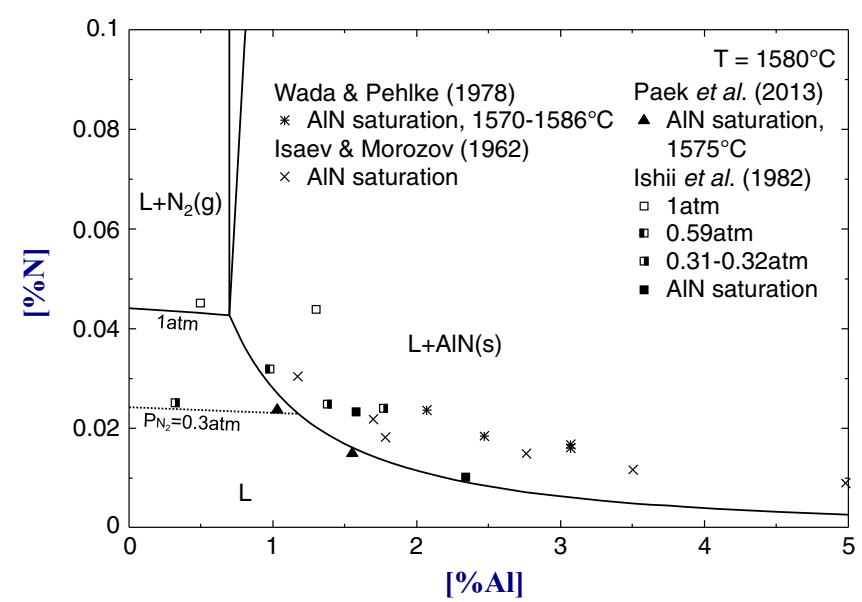

(b)

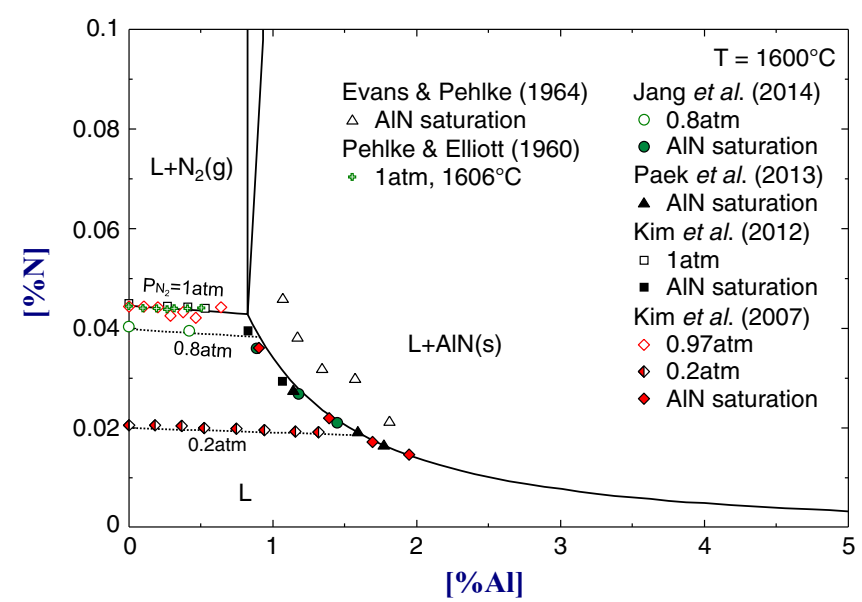

(c)

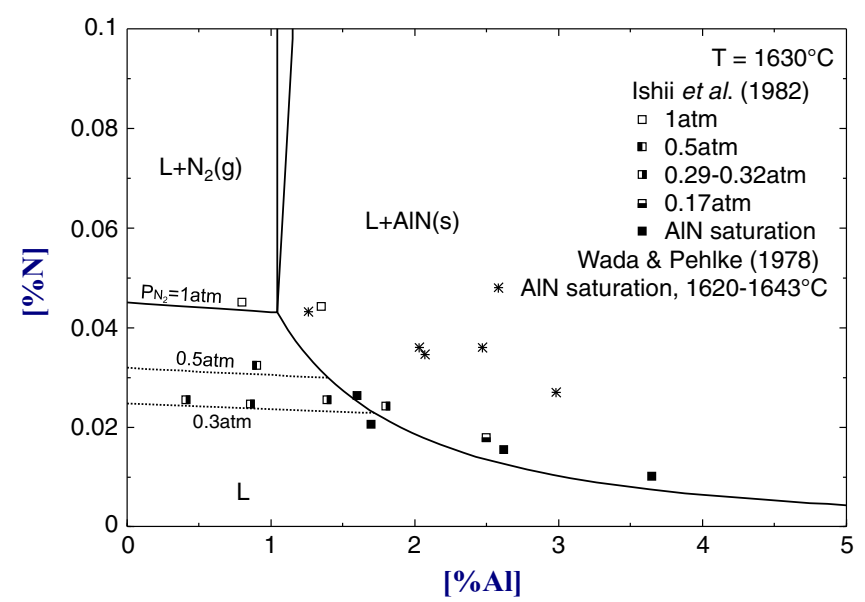

(d)

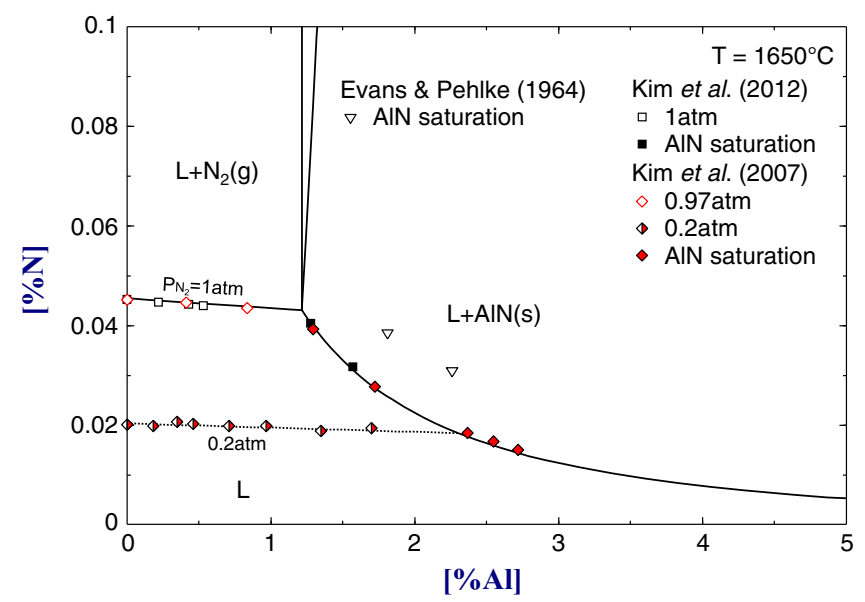

(e)

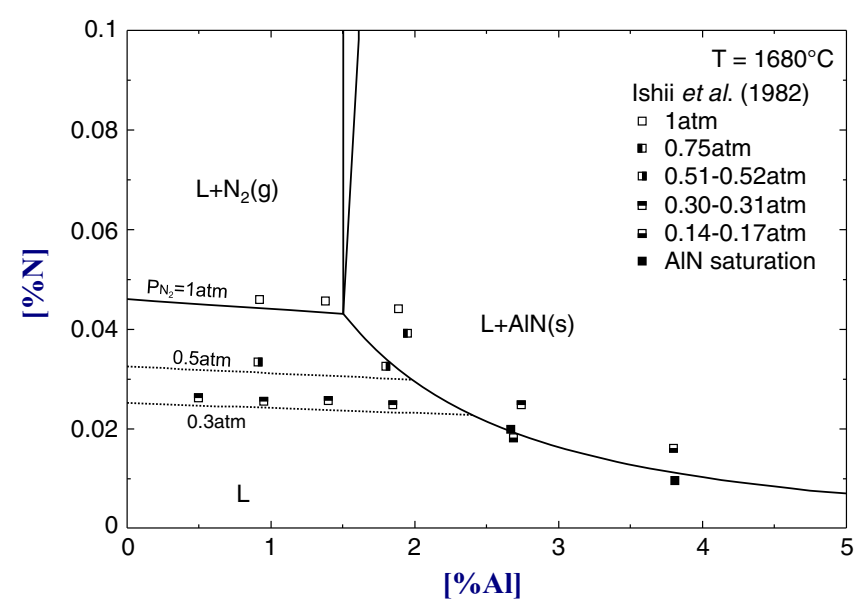

(f)

Fig. 10 - Comparison between experiments ${ }^{[5,33,45,46,73,79-82]}$ and model calculations for equilibrium Al-N relation in liquid iron.

in literatures were also plotted to test the accuracy of the calculated diagrams. The solubility limit of $\mathrm{N}$ in liquid Fe can be determined by two types of phase equilibria with $\mathrm{N}_{2}(\mathrm{~g})$ and solid AlN. At low Al concentration, the solubility of $\mathrm{N}$ is determined directly by the $\mathrm{N}_{2}(\mathrm{~g})$ formation and thus dependent on the partial pressure of $\mathrm{N}_{2}$ (g). Recent experimental data by Jang et al., ${ }^{[79]} \mathrm{Kim}$ et al., ${ }^{[46]}$ and Kim et al., ${ }^{[45]}$ and the previous data by Ishii et al., ${ }^{[73]}$ and Pehlke and Elliott ${ }^{[33]}$ show that the $\mathrm{N}$ solubility in liquid $\mathrm{Fe}$ in equilibration with $\mathrm{N}_{2}$ gas is decreasing with increasing Al content which is very well predicted in the present calculations. Regarding the solubility limit of AlN (that is, liquidus of AlN) in liquid $\mathrm{Fe}$, the experimental data are rather scattered. In 


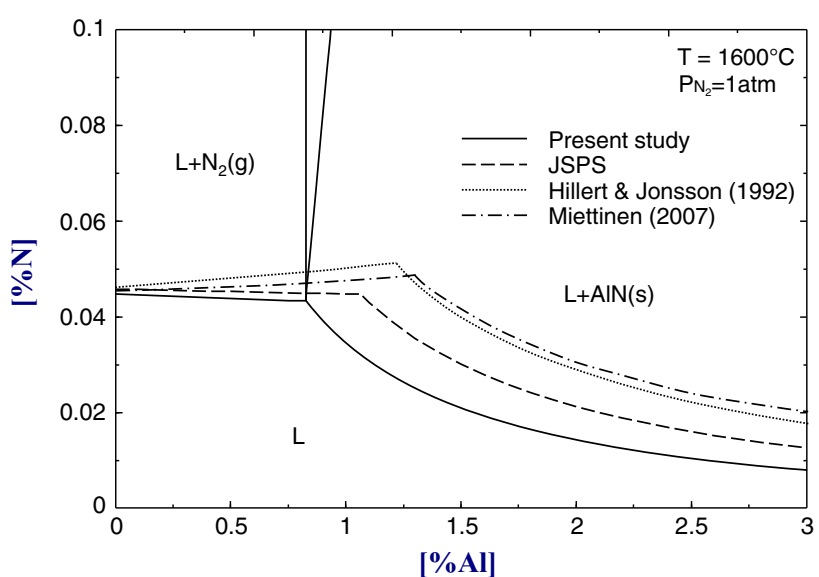

Fig. 11-Comparison of the calculated $\mathrm{N}$ solubility in the $\mathrm{Fe}-\mathrm{Al}$ melt at $1873 \mathrm{~K}\left(1600{ }^{\circ} \mathrm{C}\right)$ from various thermodynamic assessments.

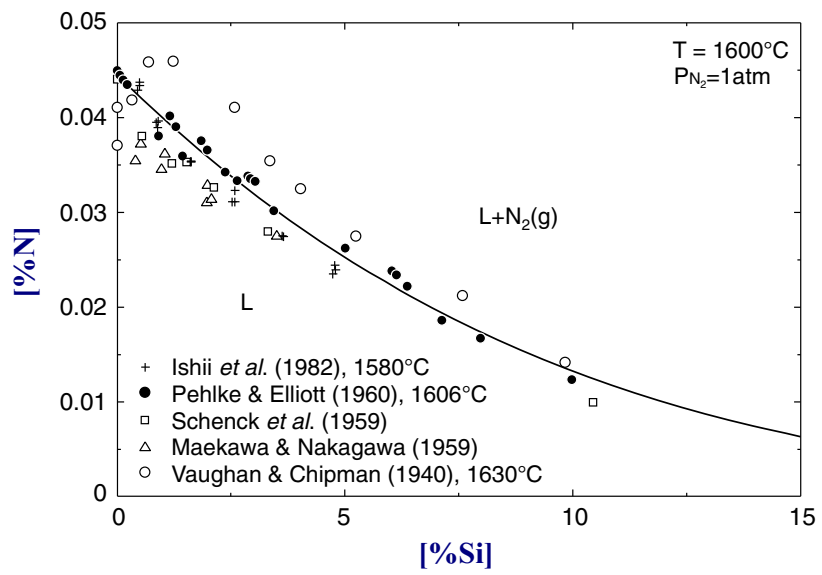

(a)

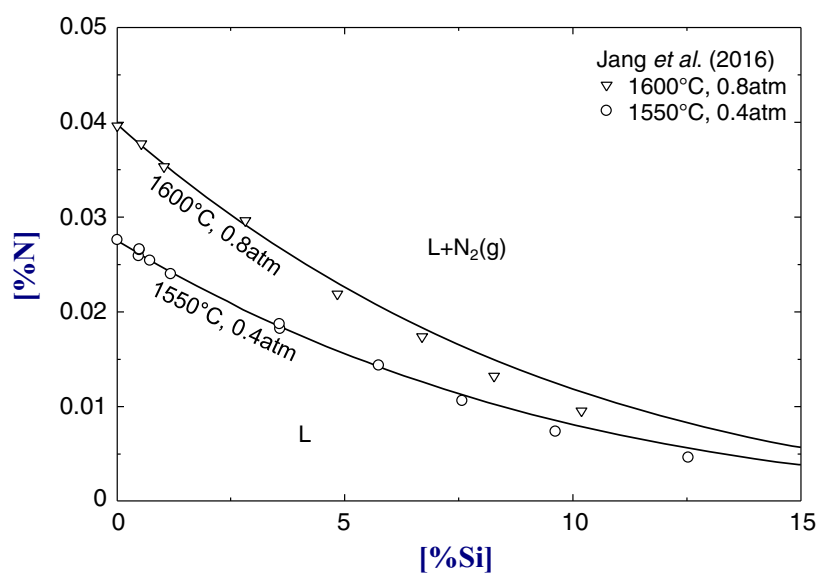

(b)

Fig. 12-Comparison between experiments ${ }^{[33,54,55,73,75,94]}$ and model calculations for $\mathrm{N}$ solubility in Fe-Si melts at $(a) 1873 \mathrm{~K}\left(1600{ }^{\circ} \mathrm{C}\right)$ under $1 \mathrm{~atm} \mathrm{~N}_{2}$ pressure and (b) $1823 \mathrm{~K}$ to $1873 \mathrm{~K}\left(1550{ }^{\circ} \mathrm{C}\right.$ to $1600{ }^{\circ} \mathrm{C}$ ) under reduced $\mathrm{N}_{2}$ partial pressures.

general, recent results using sampling technique $^{[5,45,46,73,79]}$ show lower solubility limit than the earlier works based on the Sieverts' method.$^{[80-82]}$ In the recent sampling experiments, ${ }^{[5,45,46,79]}$ the authors checked the samples very carefully using SEM to demonstrate that their liquid $\mathrm{Fe}$ was really saturated with solid AlN and no solid AlN is entrained in liquid metal sample for the analyses of soluble $\mathrm{Al}$ and $\mathrm{N}$. Unfortunately, it is difficult to find such details of analysis in the previous works using Sieverts' method. Therefore, the recent experimental works were more favored in the present thermodynamic modeling. It should be noted that this solubility limit of AlN is already taken into account in the determination of the Gibbs energy of solid AlN as described above.

Figure 11 shows the comparison of the calculated phase diagrams of the Fe-Al-N system at $1873 \mathrm{~K}$ $\left(1600{ }^{\circ} \mathrm{C}\right)$ from various thermodynamic assessments. The solubility limit of AIN in molten iron is highly dependent on the Gibbs energy of AlN used in each assessment. The present modeling work puts more weight on the recent experimental data while the JSPS evaluation was based on Wada et al. ${ }^{[80]}$, $s$ experimental results using the Sieverts' method. Therefore, there is noticeable difference in the solubility limit of AlN in the calculated diagrams. The calculated $\mathrm{N}$ solubility results from Hillert and Jonsson ${ }^{[84]}$ and Miettinen ${ }^{[85]}$ are much higher than the experimental data. The slope of the phase boundary against $\mathrm{N}_{2}(\mathrm{~g})$ from the present work and JSPS is slightly negative and agrees with experimental data, while the results from the classical CALPHAD-type assessments with BWRMM ${ }^{[84,85]}$ show slight positive slope. This difference results from the parameter used for liquid Al-N solution. In the present MQM description, no parameter for the Al-N interaction $\left(\Delta g_{\text {AIN }}=0\right)$ was used, and the WIPF description by JSPS used positive interaction parameter between Al and $\mathrm{N}$. While, negative interaction parameters were introduced in the BWRMM description.

\section{3. $\mathrm{Fe}-\mathrm{Si}-\mathrm{N}$ system}

The $\mathrm{N}$ solubility in the Fe-Si melts was measured by the Sieverts' method ${ }^{[33,94]}$ and the sampling method. ${ }^{[5,55,73,75]}$ All the literature data for $\mathrm{N}$ solubility in liquid $\mathrm{Fe}$ equilibrated with $\mathrm{N}_{2}$ gas at $1 \mathrm{~atm}$ and less than $1 \mathrm{~atm}$ pressures are plotted together in Figure 12. Although the experimental data by Vaughan and Chipman ${ }^{[94]}$ using the Sieverts' method indicated a maximum $\mathrm{N}$ solubility at low $\mathrm{Si}$ concentration region due to unknown reason, later studies ${ }^{[33,54,55,73,75]}$ confirmed that the $\mathrm{N}$ solubility continuously decreases with increasing Si. The interaction parameter between $\mathrm{Si}$ and $\mathrm{N}$ in the WIPF was determined based on the experimental data in this Fe-Si-N system. The present MQM parameter of $\Delta g_{\mathrm{SiN}}$ was determined to reproduce the experimental data in Figure 12. A slightly positive but constant $\Delta g_{\mathrm{SiN}}$ can reproduce the solubility data of $\mathrm{N}$ in the Fe-Si melts.

\section{4. $\mathrm{Fe}-\mathrm{C}-\mathrm{N}$ system}

The variation of $\mathrm{N}$ solubility in liquid $\mathrm{Fe}$ depending on carbon content was measured using the sampling method $\mathrm{d}^{[33,47,54,55,73]}$ and the levitation melting technique $^{[39,40,95]}$ at the temperature range between $1773 \mathrm{~K}$ and $2273 \mathrm{~K}\left(1500{ }^{\circ} \mathrm{C}\right.$ and $\left.2000{ }^{\circ} \mathrm{C}\right)$. All the experimental data are plotted in Figure 13. The Sieverts' method was 


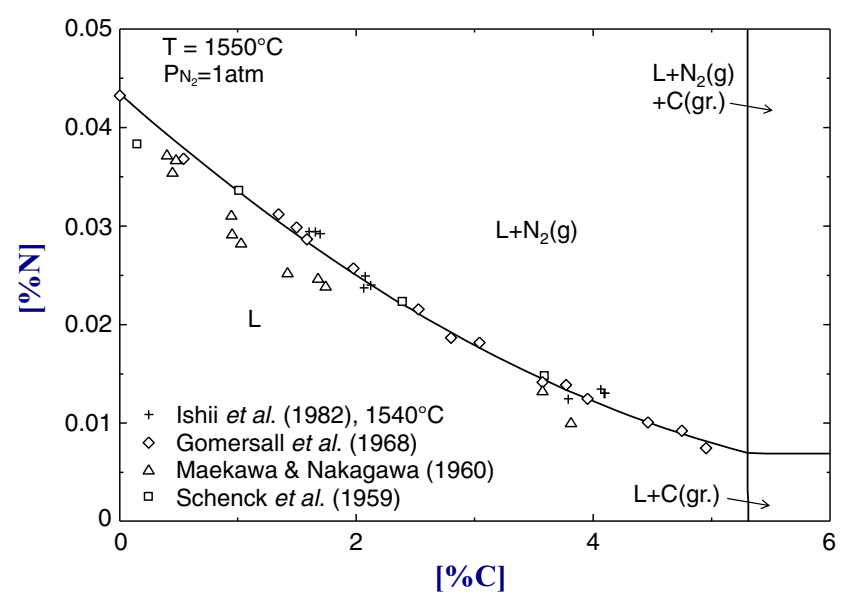

(a)

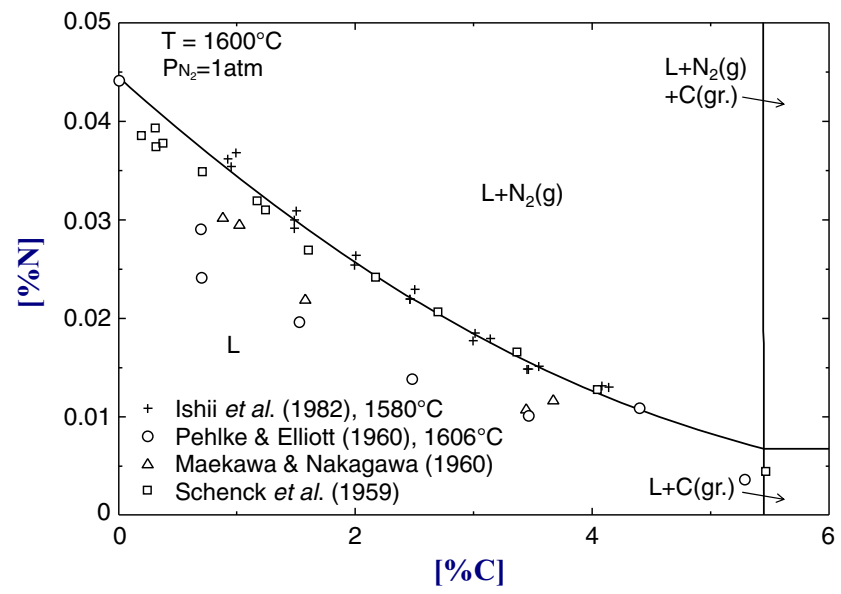

(b)

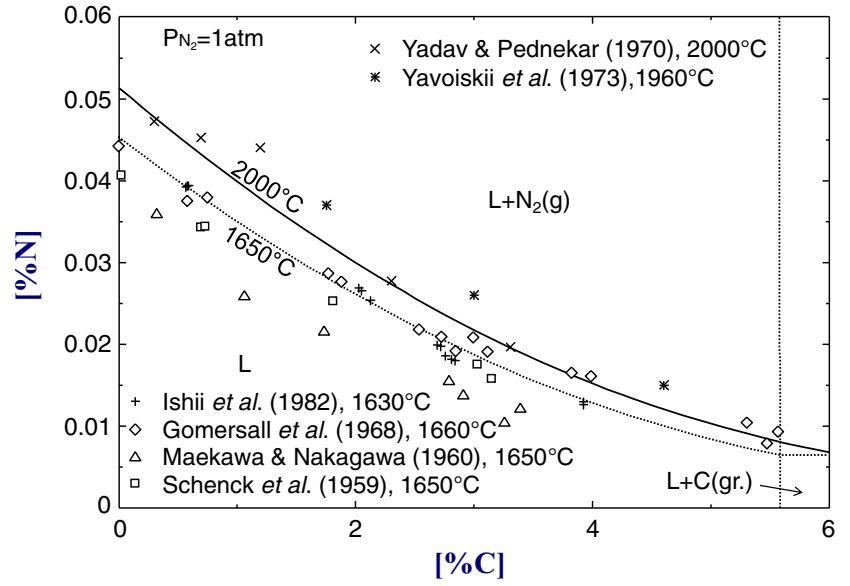

(c)

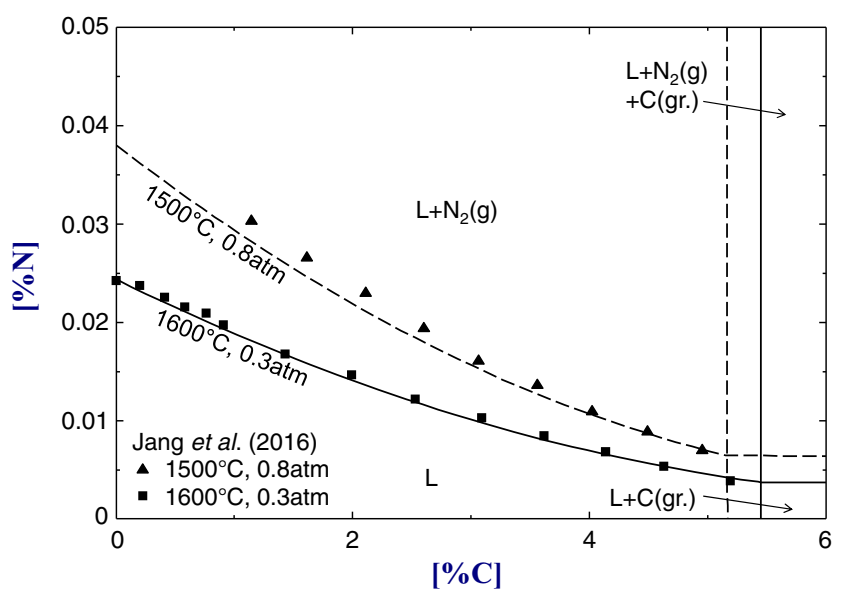

(d)

Fig. 13 - Comparison between experiments ${ }^{[33,39,40,47,54,55,73,75]}$ and model calculations for $\mathrm{N}$ solubility in Fe-C melts at $(a) 1823 \mathrm{~K}\left(1550{ }^{\circ} \mathrm{C}\right),(b)$ $1873 \mathrm{~K}\left(1600{ }^{\circ} \mathrm{C}\right),(c) 1923 \mathrm{~K}$ to $2273 \mathrm{~K}\left(1650{ }^{\circ} \mathrm{C}\right.$ to $\left.2000{ }^{\circ} \mathrm{C}\right)$ under $1 \mathrm{~atm} \mathrm{~N}_{2}$ pressure, (d) $1773 \mathrm{~K}$ to $1873 \mathrm{~K}\left(1500{ }^{\circ} \mathrm{C}\right.$ to $\left.1600{ }^{\circ} \mathrm{C}\right)$ under reduced $\mathrm{N}_{2}$ partial pressures of 0.8 and $0.3 \mathrm{~atm}$.

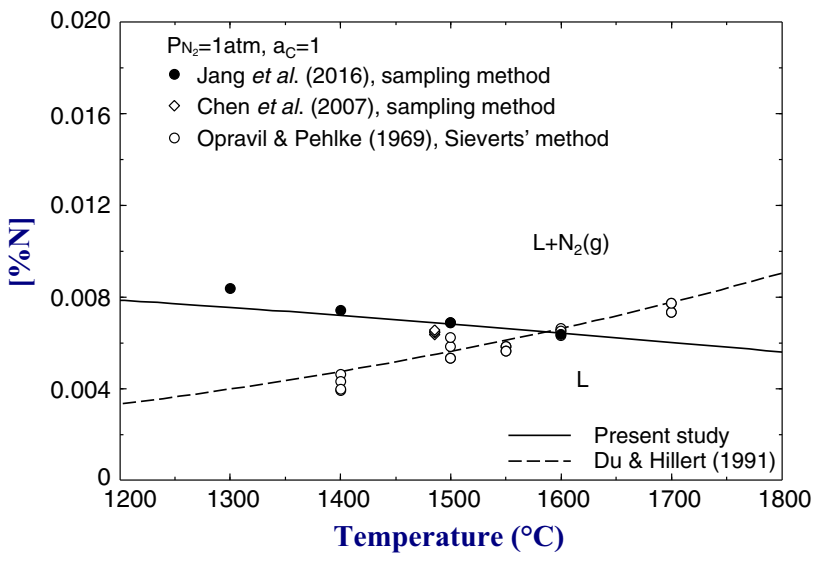

Fig. $14-\mathrm{N}$ solubility in carbon saturated liquid iron at $1 \mathrm{~atm} \mathrm{~N}_{2}$ pressure $^{[75,96,98]}$ along with the present optimization and previous modeling result. ${ }^{[97]}$

not employed in this system because carbon monoxide gas formed by the reaction between liquid $\mathrm{Fe}-\mathrm{C}$ alloy and the crucible can interfere with the gas measurements. ${ }^{[33]}$ Except Maekawa and Nakagawa ${ }^{[54]}$ and Pehlke and Elliott ${ }^{[33]}$,s data, other results measured by the sampling ${ }^{[55,73]}$ and levitation method ${ }^{[39,40,95]}$ under $1 \mathrm{~atm} \mathrm{~N}_{2}$ pressure are consistent each other. Like the above $\mathrm{Fe}-\mathrm{Si}-\mathrm{N}$ system, a constant MQM parameter of $\Delta g_{\mathrm{CN}}$ was determined to reproduce the experimental $\mathrm{N}$ solubility. A positive parameter was optimized to reproduce the experimental data mainly from Ishii et al. ${ }^{[73]}$ Gomersall et al. ${ }^{[39]}$ and Schenck et al. ${ }^{[55]}$ at $1 \mathrm{~atm} \mathrm{~N}_{2}$ pressure and from Jang et al. ${ }^{[47]}$ under reduced $\mathrm{N}_{2}$ partial pressures of 0.3 and 0.8 atm. It should be noted that the JSPS's positive interaction parameter between $\mathrm{C}$ and $\mathrm{N}$ for the WIPF was also determined in this system mainly based on the experimental data by Ishii et al. ${ }^{[73]}$.

The $\mathrm{N}$ solubility was also measured in $\mathrm{C}$ saturated liquid iron as shown in Figure 14. Opravil and Pehlke ${ }^{[96]}$ measured the $\mathrm{N}$ solubility in $\mathrm{Fe}-\mathrm{C}_{\mathrm{sat}}$ melt in the temperature range from $1673 \mathrm{~K}$ to $1973 \mathrm{~K}\left(1400{ }^{\circ} \mathrm{C}\right.$ to $1700{ }^{\circ} \mathrm{C}$ ) using the Sieverts' method. They reported that the $\mathrm{N}$ solubility in $\mathrm{C}$ saturated melts increased with increasing temperature, and the results were in good agreement with $\mathrm{Du}$ and Hillert ${ }^{[97]}$ for the previous 


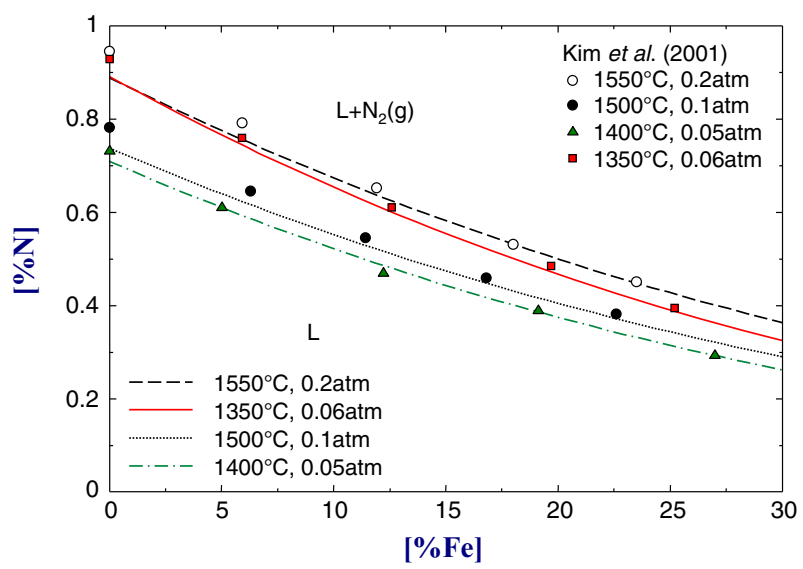

(a)

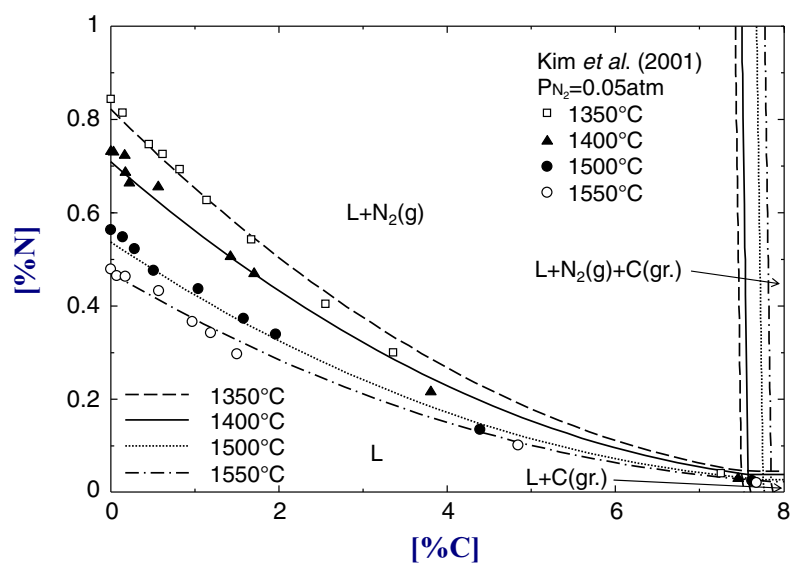

(b)

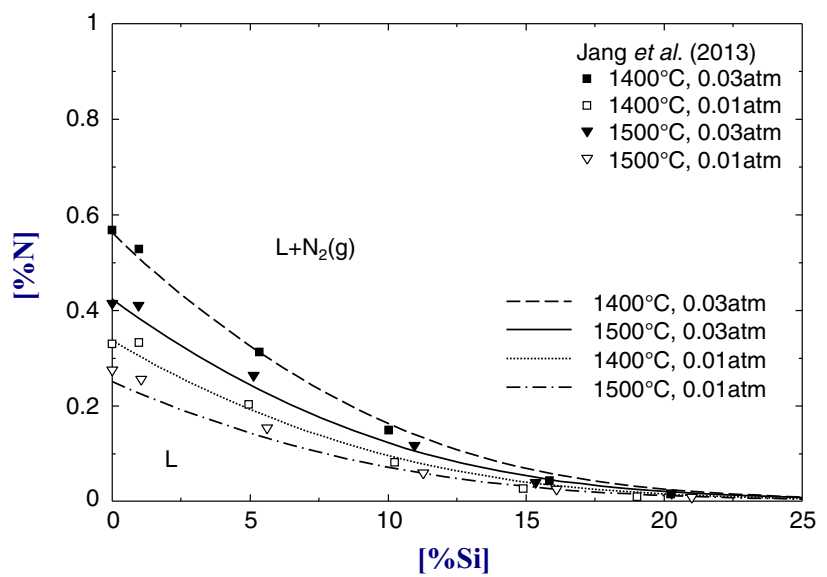

(c)

Fig. 15-Comparison between experiments ${ }^{[34,63]}$ and model calculations for $\mathrm{N}$ solubility in (a) Mn-Fe, (b) Mn-C, and (c) Mn-Si alloy melts at various temperatures and $\mathrm{N}_{2}$ partial pressures.

optimization of this ternary liquid solution using BWRMM. However, the recent measurements by Jang et al. ${ }^{[75]}$ using the sampling method show the opposite temperature dependence. This discrepancy in temperature dependency can be also seen in other systems like $\mathrm{Fe}-\mathrm{Mn}-\mathrm{C}_{\mathrm{sat}}$ and $\mathrm{Fe}-\mathrm{Si}-\mathrm{C}_{\text {sat }}$ melts between these two studies. Most possible explanation of this discrepancy can be found from the experimental procedure of
Opravil and Pehlke. ${ }^{[96]}$ Opravil and Pehlke ${ }^{[96]}$ performed the continuous measurement of $\mathrm{N}$ solubility with increasing temperature. At starting temperature, liquid $\mathrm{Fe}$ would be reasonably well saturated by $\mathrm{C}$ from graphite crucible. But they increased the temperature continuously during the experiment and maintained only for about 15 minutes at each measurement temperature. The dissolution of graphite to liquid melts would not be fast enough for $\mathrm{C}$ saturation within such a short duration time; the recent experimental data by Jang et al. ${ }^{[75]}$ confirmed that the $\mathrm{C}$ saturation required at least 1 hour in the similar temperature range even when they used an induction furnace. Therefore, the liquid Fe in the experiment by Opravil and Pehlke ${ }^{[96]}$ was most probably away from the $\mathrm{C}$ saturation condition. If the $\mathrm{C}$ content in liquid $\mathrm{Fe}$ is fixed to be $4.88 \mathrm{wt}$ pct (saturation $\mathrm{C}$ amount at $1673 \mathrm{~K}\left(1400{ }^{\circ} \mathrm{C}\right)$ ), the $\mathrm{N}$ solubility in liquid $\mathrm{Fe}-\mathrm{C}$ calculated from the present model increases from $76 \mathrm{ppm}$ at $1400{ }^{\circ} \mathrm{C}$ to $92 \mathrm{ppm}$ at $1973 \mathrm{~K}$ $\left(1700{ }^{\circ} \mathrm{C}\right)$. On the other hand, Jang et al. ${ }^{[75]}$ confirmed the equilibrium of melt by $\mathrm{C}$ and $\mathrm{N}_{2}$ gas at each temperature by in situ analyses of $\mathrm{N}$ and $\mathrm{C}$ with time using a sampling technique. The present model is well reproducing the results of Jang et al. ${ }^{[75]}$ without any additional parameters. The decreasing nitrogen solubility in liquid $\mathrm{Fe}-\mathrm{C}_{\text {sat }}$ with increasing temperature can be caused mainly by the increasing $\mathrm{C}$ content in liquid $\mathrm{Fe}$. As there is strong positive interaction between $\mathrm{C}$ and $\mathrm{N}$ in liquid $\mathrm{Fe}$, the increasing $\mathrm{C}$ content in the melt can decrease the $\mathrm{N}$ solubility. If the results of Opravil and Pehlke ${ }^{[96]}$ were reproduced, ternary model parameters were necessary. It should be also noted that the experimental result of Chen et al. ${ }^{[98]}$ at $1758 \mathrm{~K}$ $\left(1485^{\circ} \mathrm{C}\right)$ is more consistent with the results of Jang et al. ${ }^{[75]}$

\section{Mn-Fe-N, Mn-C-N, and Mn-Si-N systems}

Kim et al. ${ }^{[34]}$ and Jang et al. ${ }^{[63]}$ investigated the nitrogen solubility in the Mn-rich melt for ferro-Mn production. The experimental $\mathrm{N}$ solubilities in $\mathrm{Mn}-\mathrm{Fe}$, $\mathrm{Mn}-\mathrm{C}$, and $\mathrm{Mn}-\mathrm{Si}$ melts were determined using the sampling technique at various temperatures under reduced $\mathrm{N}_{2}$ partial pressures and the results are plotted in Figure 15. Without any additional ternary parameters, all the experimental data in the Mn-rich melts are also accurately predicted by the present MQM model using the optimized binary parameters.

\section{PREDICTION OF $N$ SOLUBILITY IN MULTICOMPONENT ALLOY MELTS}

In this section, the predictions of the present MQM model with binary model parameters are compared to the experimental data for multicomponent melt. In the present study, only recent experimental data in the Fe-Al-Mn-Si-C melt were collected for this comparison.

\section{A. Fe-Mn-Si-N, Fe-Mn-C-N, and Fe-Si-C-N Systems}

Recently, Jang et al. ${ }^{[75]}$ measured the $\mathrm{N}$ solubility in the Fe-Mn-Si, Fe-Mn-C, and Fe-Si-C alloy melts at 


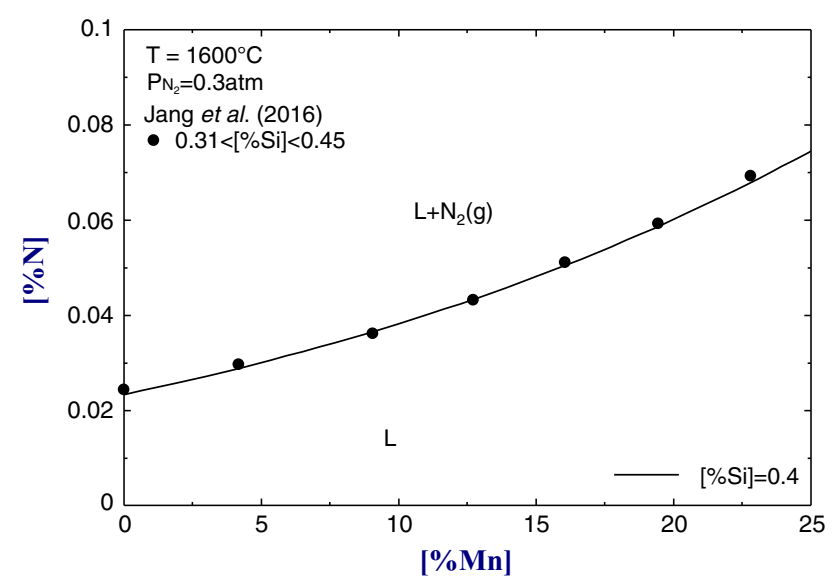

Fig. 16-Calculated $\mathrm{N}$ solubility in Fe-Mn-Si melts at $1873 \mathrm{~K}$ $\left(1600{ }^{\circ} \mathrm{C}\right)$ under $0.3 \mathrm{~atm} \mathrm{~N}_{2}$ partial pressure along with experimental data. ${ }^{[75]}$

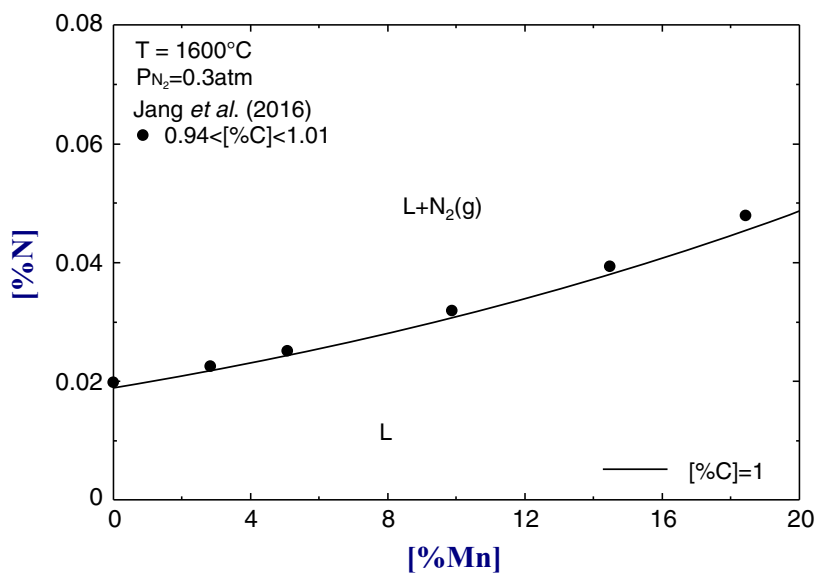

Fig. 17-Calculated $\mathrm{N}$ solubility in Fe-Mn-C melts at $1873 \mathrm{~K}$ $\left(1600{ }^{\circ} \mathrm{C}\right)$ under $0.3 \mathrm{~atm} \mathrm{~N}_{2}$ partial pressure along with experimental data. ${ }^{[75]}$

$1873 \mathrm{~K}\left(1600{ }^{\circ} \mathrm{C}\right)$ under reduced $\mathrm{N}_{2}$ partial pressures in order to determine the simultaneous effects of alloying elements on the $\mathrm{N}$ solubility in these melts. They carried out the sampling experiment after equilibrating the melt under reduced $\mathrm{N}_{2}$ gas pressure, which could reduce the chance of a loss of $\mathrm{N}$ during sampling. For the Fe-Mn-Si and $\mathrm{Fe}-\mathrm{Mn}-\mathrm{C}$ systems, they carried out the experiment with variation of $\mathrm{Mn}$ concentration up to $25 \mathrm{wt}$ pct. Uda and Pehlke ${ }^{[99]}$ and Schenck et al. ${ }^{[55]}$ also investigated the $\mathrm{N}$ solubility in the $\mathrm{Fe}-\mathrm{Si}-\mathrm{C}$ melts under $1 \mathrm{~atm}$ $\mathrm{N}_{2}$ pressure using the levitation and sampling method, respectively. All these experimental data were accurately predicted from the present model with only binary model parameters, as can be seen in Figures 16 through 18.

Figure 19 shows the $\mathrm{N}$ solubility in $\mathrm{C}$ saturated liquid iron alloys containing $\mathrm{Mn}$ and Si. Opravil and Pehlke ${ }^{[96]}$ and Jang et al. ${ }^{[75]}$ measured the $\mathrm{N}$ solubility in Fe-Mn- $\mathrm{C}_{\mathrm{sat}}$ and Fe-Si- $\mathrm{C}_{\text {sat }}$ melts using the Sieverts' method and sampling method, respectively. The two

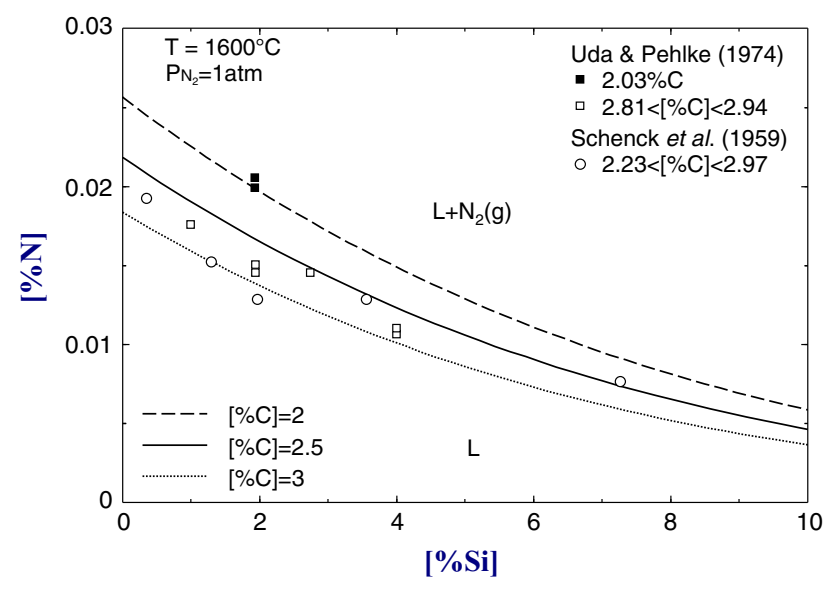

Fig. 18 - Comparison between experiments ${ }^{[55,99]}$ and model calculations for $\mathrm{N}$ solubility in Fe-Si-C melts at $1873 \mathrm{~K}\left(1600{ }^{\circ} \mathrm{C}\right)$ under $1 \mathrm{~atm} \mathrm{~N}_{2}$ partial pressure.

experimental studies show the opposite trend in temperature dependency. As explained above in Section III-C-4. for liquid $\mathrm{Fe}-\mathrm{C}_{\text {sat }}$ (see Figure 14), because the experimental results of Opravil and Pehlke ${ }^{[96]}$ might not reach the carbon saturation condition during the progress of the experiment, their data were not considered. The present model can accurately predict the experimental results by Jang et al. ${ }^{[75]}$ from optimized binary parameters. Previously, Bouchard and Bale $^{[100]}$ attempted to reproduce the results of Opravil and Pehlke ${ }^{[96]}$ using the UIPF. The reproduction of the experimental data required unusually many binary, ternary, and quaternary interaction parameters with temperature dependence. Compared to the calculated nitrogen solubility line for $\mathrm{Fe}-\mathrm{C}_{\text {sat }}$ melt, $\mathrm{Mn}$ increases the nitrogen solubility while $\mathrm{Si}$ decreases it in $\mathrm{Fe}-\mathrm{C}_{\mathrm{sat}}$ melts as shown in Figure 19.

\section{B. Fe-Si-Al-N, $\mathrm{Fe}-\mathrm{C}-\mathrm{Al}-\mathrm{N}$, and $\mathrm{Fe}-\mathrm{Mn}$-Al-N Systems}

The effects of $\mathrm{Si}, \mathrm{C}$, and $\mathrm{Mn}$ on the solubility of AlN in liquid iron have been measured using the metal/ AlN/gas equilibration technique. ${ }^{[5,46,79,101]}$ Kim et al. ${ }^{[46]}$ measured the effect of $\mathrm{Si}$ on the AlN solubility product in liquid $\mathrm{Fe}-\mathrm{Al}$ alloy in the temperature range from $1823 \mathrm{~K}$ to $1923 \mathrm{~K}\left(1550{ }^{\circ} \mathrm{C}\right.$ to $\left.1650{ }^{\circ} \mathrm{C}\right)$. In the Fe-C-Al-N ${ }^{[79]}$ and Fe-Mn-Al-N ${ }^{[5,101]}$ systems, the experiments were carried out even below the typical steelmaking temperature because $\mathrm{C}$ and $\mathrm{Mn}$ significantly decrease the melting temperature of the steels. C content was varied up to $3.9 \mathrm{wt}$ pct, and $\mathrm{Mn}$ was added up to about $22 \mathrm{wt}$ pct. It was found that both $\mathrm{Si}$ and $\mathrm{C}$ decrease the solubility of AlN in liquid iron while $\mathrm{Mn}$ increases it mainly due to the affinity of $\mathrm{N}$ with each alloying element. These experimental data were used to derive the influence of the second alloying element on the interaction parameters between the first alloying element and $\mathrm{N}$ in the classical WIPF description. ${ }^{[5,46,79,101]}$ That is, the WIPF needs additional correction terms (ternary interaction term) for interaction parameter. On the other hand, as can be seen in 


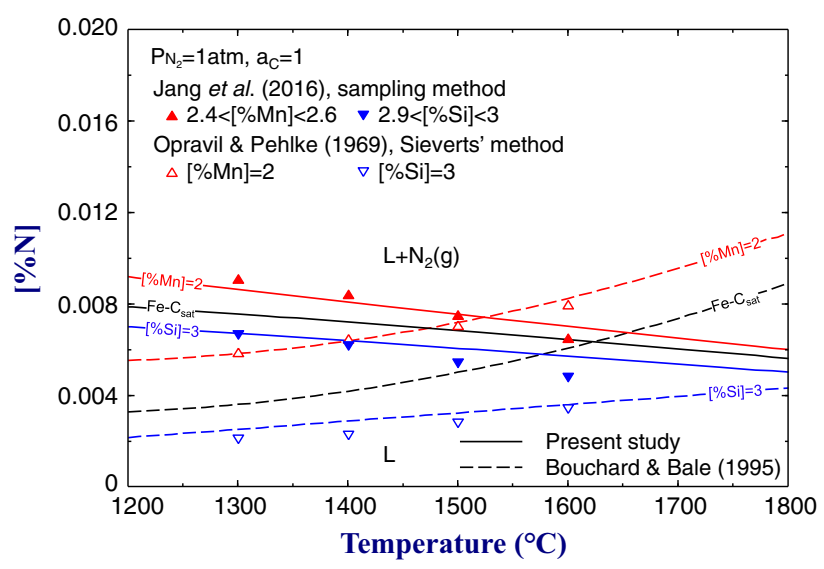

Fig. 19- N solubility in $\mathrm{Fe}-\mathrm{Mn}-\mathrm{C}_{\mathrm{sat}}$ and $\mathrm{Fe}-\mathrm{Si}-\mathrm{C}_{\mathrm{sat}}$ melts at $1 \mathrm{~atm}$ $\mathrm{N}_{2}$ pressure ${ }^{[75,97]}$ along with the present optimization and previous modeling result. ${ }^{[100]}$

Figures 20 through 22, no additional parameters other than binary parameters were required in the present study using the MQM to accurately predict the nitrogen solubility in these melts.

\section{C. $\mathrm{Fe}-\mathrm{Mn}$-Al-Si-C-N System}

Although this is very important system for the TWIP steel production, very limited study has been carried out for the dissolution of $\mathrm{N}$ in the melt. Very recently, Jang et al. ${ }^{[101]}$ performed the equilibrium experiment between liquid TWIP steel and $\mathrm{N}_{2}$ gas. They measured the critical $\mathrm{N}$ contents for the onset of the AIN formation and investigated the evolution of AlN inclusion in the Fe-Mn-Si-C-Al melt (Fe-23.75Mn-0.33Si-0.59C-1.3Al in wt pet) during cooling. As shown in Figure 23, the present MQM model with binary parameters can accurately predict the solubility limit of AlN in this melt at the temperatures between $1723 \mathrm{~K}$ and $1823 \mathrm{~K}$ $\left(1450{ }^{\circ} \mathrm{C}\right.$ and $\left.1550{ }^{\circ} \mathrm{C}\right)$.

\section{Mn-Based Alloy Systems}

Figure 24 shows the experimental $\mathrm{N}$ solubility results for the Mn-Fe-C, Mn-Fe-Si, Mn-Si-C, and Mn-Fe-Si-C melts at the temperature range between $1673 \mathrm{~K}$ and $1773 \mathrm{~K}\left(1400{ }^{\circ} \mathrm{C}\right.$ and $\left.1500{ }^{\circ} \mathrm{C}\right)$ under reduced $\mathrm{N}_{2}$ gas pressure. These experiments were carried out by Kim et al. ${ }^{[34]}$ and Jang et al. ${ }^{[63]}$ for the aiming of understanding of $\mathrm{N}$ dissolution in ferro-Mn melts. All these experimental data in Mn-rich melts were also well predicted by the present MQM model with the identical model parameters used for Fe-rich melt.

\section{DISCUSSIONS}

Although WIPF is relative simple formula to use for equilibration calculations, different sets of interaction parameters would be required depending on the target melt composition. For example, Sigworth and Elliott

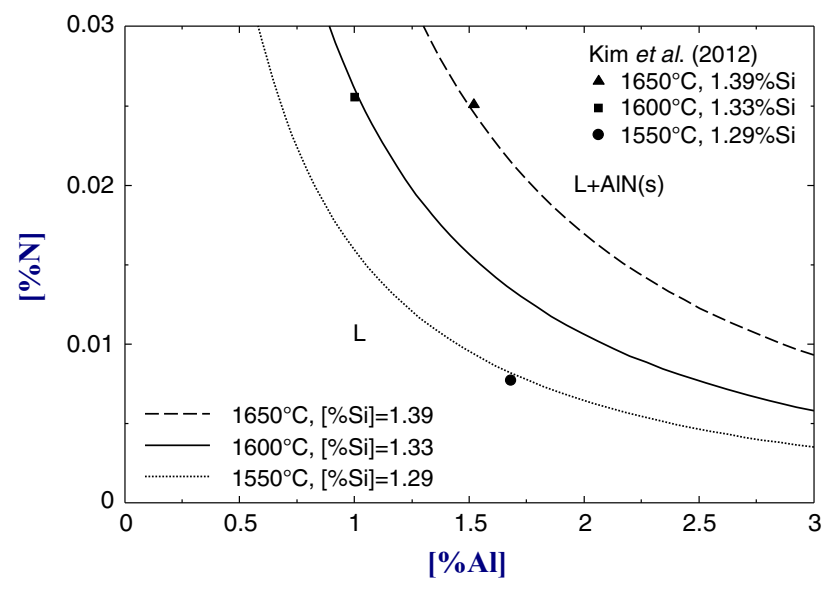

Fig. 20-Calculated equilibrium solubility of AlN in Fe-Si-Al alloy melts at $1823 \mathrm{~K}$ to $1923 \mathrm{~K}\left(1550{ }^{\circ} \mathrm{C}\right.$ to $\left.1650{ }^{\circ} \mathrm{C}\right)$ along with the experimental results. ${ }^{[46]}$

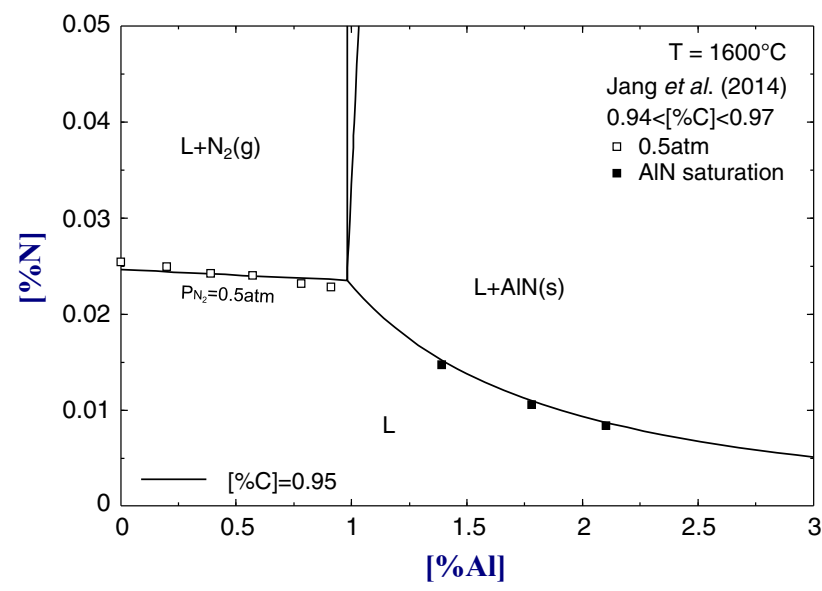

Fig. 21-Calculated equilibrium solubility of $\mathrm{N}$ in $\mathrm{Fe}-\mathrm{C}-\mathrm{Al}$ alloy melts at $1873 \mathrm{~K}\left(1600^{\circ} \mathrm{C}\right)$ along with the experimental results ${ }^{[79]}$.

optimized the different sets of the Henrian activity coefficients and interaction parameters for different base metals like $\mathrm{Fe}_{-},{ }^{[12]} \mathrm{Cu}-{ }^{[102]} \mathrm{Ni}-{ }^{[103]}$ and $\mathrm{Co}-$ rich $^{[104]}$ melts. One of the striking advantages of the present MQM approach compared to the WIPF is that the thermodynamic properties (Gibbs energy) of the entire composition range of the Fe-Al-Mn-Si-C melt can be accurately described by one set of parameter. The other big advantage of the MQM approach is that small number of model parameters is in general required in comparison to the WIPF approach. For example, in order to reproduce all $\mathrm{N}$ solubility in the entire Fe-Al-Mn-Si-C melts, only 3 binary $\mathrm{N}$ parameters were required, while the WIPF would require many folds of interaction parameters related to $\mathrm{N}$ to get reasonable accuracy in the same high alloy system.

Figure 25 shows the comparison between different thermodynamic assessments and databases for TWIP steel composition (Fe-20Mn-0.6C-Al in wt pct). The results from the FactSage FTmisc-FeLQ database based 


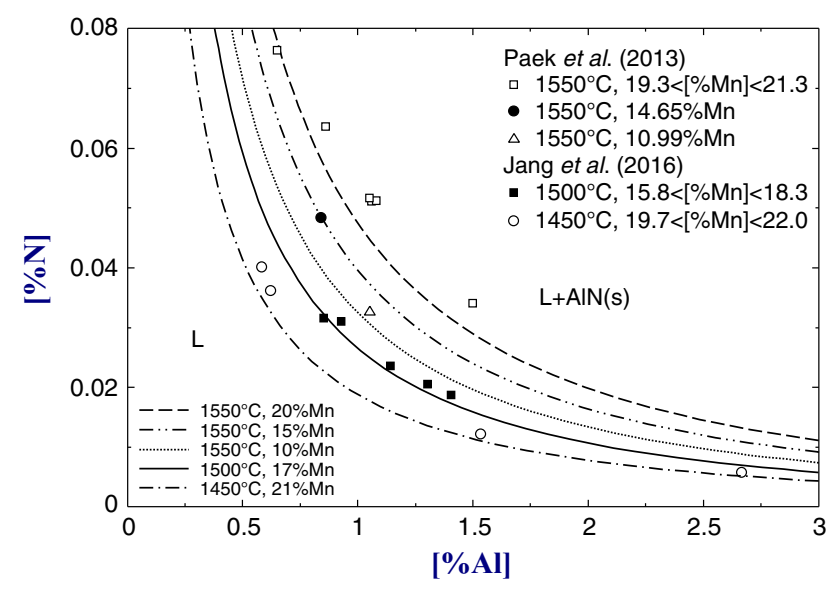

Fig. 22-Calculated equilibrium solubility of AlN in Fe-Mn-Al alloy melts along with the experimental results ${ }^{[5,101]}$ at $1723 \mathrm{~K}$ to $1823 \mathrm{~K}$ $\left(1450{ }^{\circ} \mathrm{C}\right.$ to $\left.1550{ }^{\circ} \mathrm{C}\right)$.

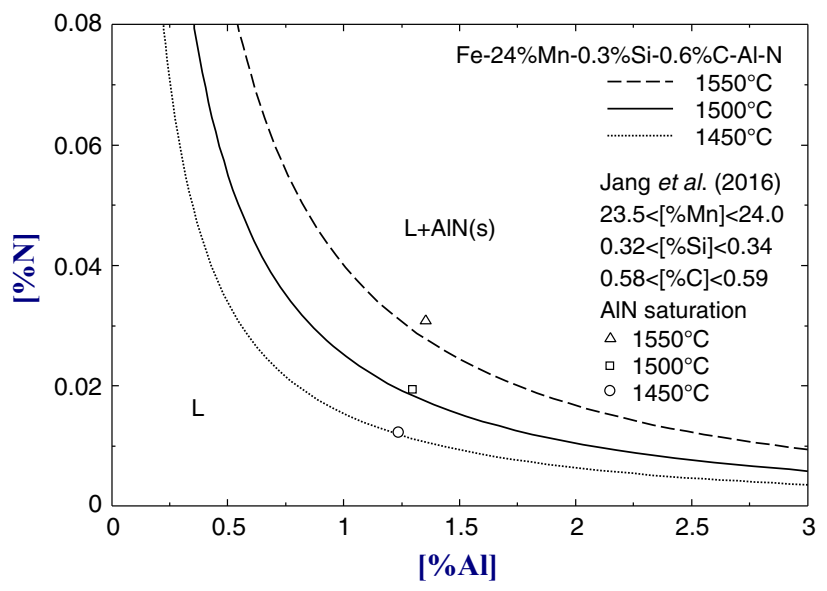

Fig. 23-Calculated equilibrium AIN solubility in Fe-Mn-Al-Si-C alloy melts along with the experimental results. ${ }^{[101]}$

on the WIPF (UIPF) and FactSage FSStel database with BWRMM were compared with the present optimization results. It should be noted that all $\mathrm{N}$ related parameters in the FeLQ are from the JSPS ${ }^{[11]}$ compilation, and FSStel database contains nearly the same liquid model parameters as the Thermo-Calc TCFE database. ${ }^{[8]}$ So the results in Figure 25 show a reasonable comparison of accuracy between the most conventionally used models with optimized parameters. As can be seen in Sections III and IV, the present MQM model with optimized binary parameters is well reproducing and predicting the experimental data. Therefore, if the present model calculation is used as the reference, the calculation result from FTmisc database (WIPF; UIPF) is similar to the reference line at [wt pct Al] $<1.5$, but it overestimates the $\mathrm{N}$ solubility at higher Al concentration. The N solubility from FSStel (BWRMM) database is calculated to be systematically higher than the reference line by about 0.007 to $0.003 \mathrm{wt}$ pet at low and high $\mathrm{Al}$ concentration region.

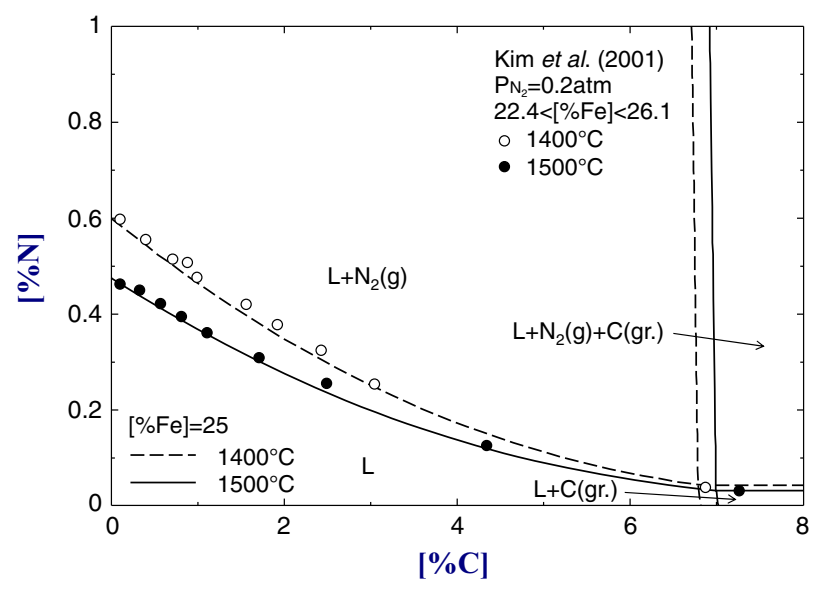

(a)

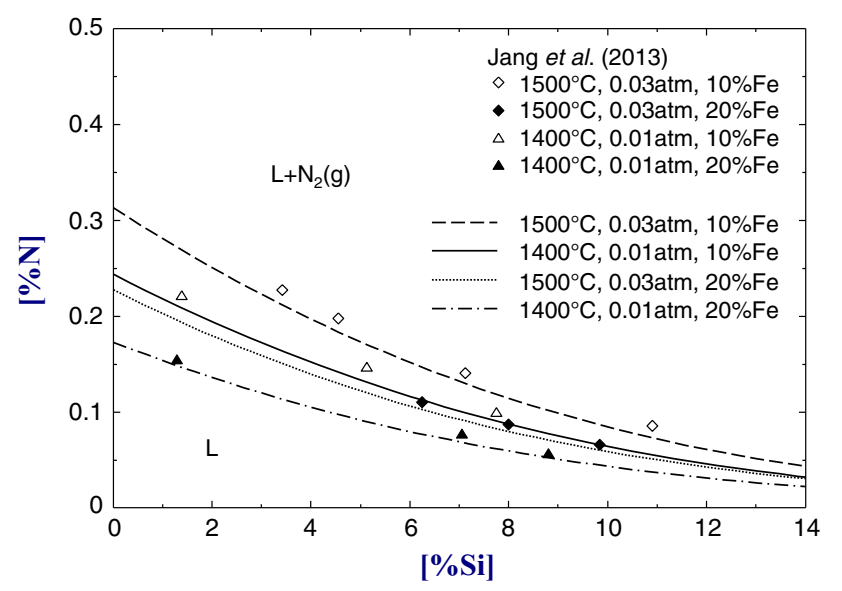

(b)

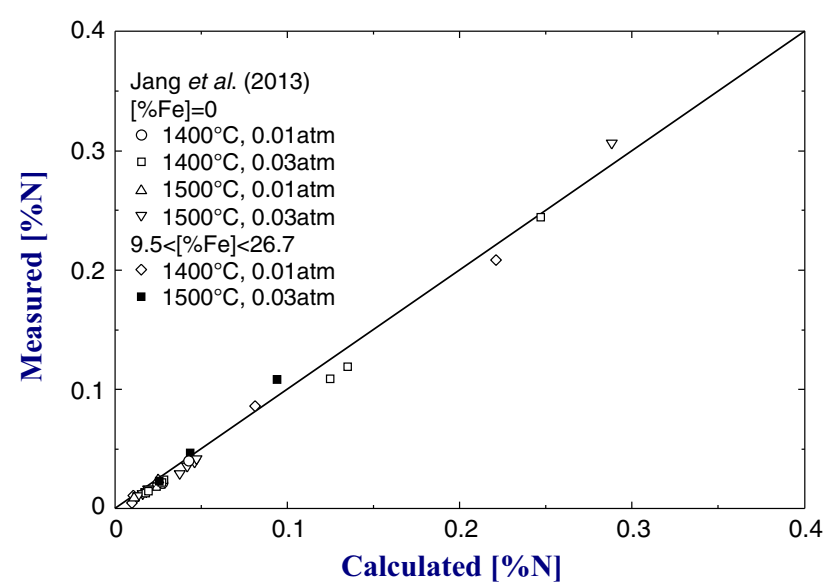

(c)

Fig. 24 Comparison between experiments ${ }^{[34,63]}$ and model calculations for $\mathrm{N}$ solubility in (a) Mn-Fe-C, (b) Mn-Fe-Si, and (c) $\mathrm{Mn}(-\mathrm{Fe})-\mathrm{Si}-\mathrm{C}$ alloy melts.

\section{SUMMARY}

The thermodynamic behavior of $\mathrm{N}$ in liquid $\mathrm{Fe}-$ Mn-Al-Si-C solution was thermodynamically optimized using the Modified Quasichemical Model (MQM). All experimental data related to $\mathrm{N}$ solubility and AlN 


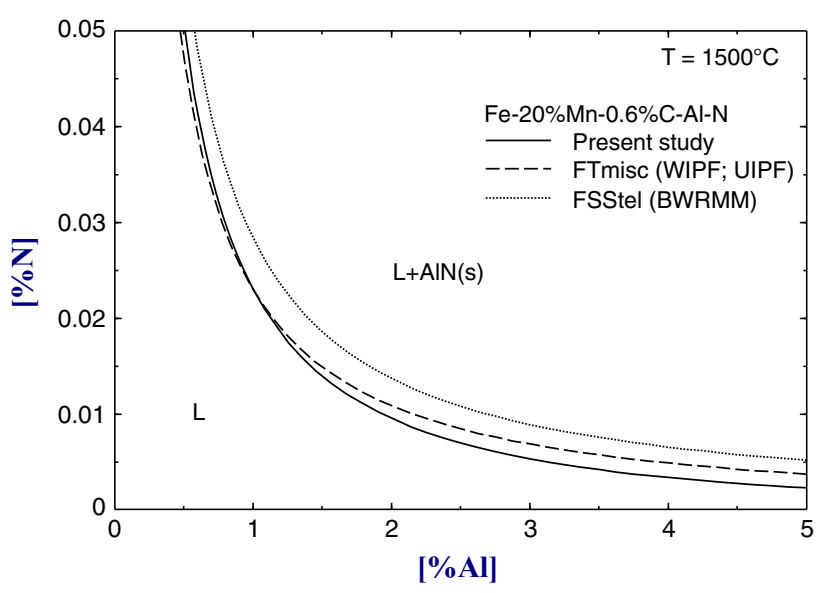

Fig. 25-Calculated AIN saturation lines of TWIP steel (Fe-Al-20Mn-0.6C in wt pct) from different thermodynamic assessments and databases.

formation in the liquid solution were critically reviewed and optimized to obtain binary model parameters of the MQM. The use of the MQM taking into account the short-range ordering of liquid species in solution and appropriate interpolation technique can minimize the number of parameters. In particular, the nitrogen solubility in the entire compositional range of ternary and high order melt of the Fe-Mn-Al-Si-C system was accurately predicted with only three binary $\mathrm{N}$ model parameters. As part of the thermodynamic optimization, the Gibbs energies of liquid $\mathrm{N}$ and solid AlN were also reassessed. This optimized database can be used, with other thermodynamic databases like oxide and gases, to perform the complex chemical reactions related to nitrogen in high alloy steel and ferro-alloy production.

\section{ACKNOWLEDGMENTS}

Financial supports from Tata Steel Europe, POSCO, RIST, Hyundai Steel, Nucor Steel, RioTinto Iron and Titanium, Nippon Steel and Sumitomo Metals Corp., JFE Steel, Voestalpine, RHI, and the Natural Sciences and Engineering Research Council of Canada are gratefully acknowledged.

\section{NOMENCLATURE}

$g_{i}^{\circ} \quad$ Molar Gibbs energy of pure component $i$ $(\mathrm{J} / \mathrm{mol})$

$X_{i} \quad$ Mole fraction of $i(-)$

$R \quad$ Gas constant, $8.314 \mathrm{~J} / \mathrm{mol} \mathrm{K}$

$T \quad$ Absolute temperature (K)

$\gamma_{i} \quad$ Raoultian activity coefficient of $i(-)$

$g_{i} \quad$ Molar Gibbs energy of pure component $i$ in infinite dilution standard state $(\mathrm{J} / \mathrm{mol})$

$f_{i} \quad$ Activity coefficient of $i$ in infinite dilution standard state $(-)$ Excess parameters between binary $i$ and $j(-)$

moles of $(i-j)$ pairs $(\mathrm{J} / \mathrm{mol})$

$n_{i} \quad$ Number of moles of $i(\mathrm{~mol})$

$n_{i j} \quad$ Number of moles of $(i-j)$ pair (mol)

$X_{i j} \quad$ Pair fraction of $(i-j)$ pair $(-)$

$Y_{i}$

$Z_{i}$
$Z_{i j}^{i}$

$\Delta S^{\text {config }}$ Coordination-equivalent fraction of $i(-)$ Coordination number of $i(-)$ Coordination number of $i$ in $i-j$ binary solution when all nearest neighbor of an $i$ are $j$ 's Configurational entropy of mixing $(\mathrm{J} / \mathrm{mol} \mathrm{K})$

\section{REFERENCES}

1. H.J. Lee, S.S. Sohn, S. Lee, J.H. Kwak, and B.J. Lee: Scripta Mater., 2013, vol. 68, pp. 339-42.

2. Q. Guo, Y.S. Chun, J.H. Lee, Y.U. Heo, and C.S. Lee: Met. Mater. Int., 2014, vol. 20, pp. 1043-51.

3. B.H. Song, J. Kim, S. Jeong, I. Choi, and Y.K. Lee: Korean J. Met. Mater., 2014, vol. 52, pp. 1-9.

4. M.K. Paek, J.M. Jang, K.H. Do, and J.J. Pak: Met. Mater. Int., 2013, vol. 19, pp. 1077-81.

5. M.K. Paek, J.M. Jang, M. Jiang, and J.J. Pak: ISIJ Int., 2013, vol. 53, pp. 973-78.

6. C. Wagner: Thermodynamics of Alloys, Addision-Wesley Press, Cambridge, MA, 1952, pp. 47-51.

7. C.W. Bale, E. Bélisle, P. Chartrand, S.A. Decterov, G. Eriksson, K. Hack, I.-H. Jung, Y.-B. Kang, J. Melançon, A.D. Pelton, C. Robelin, and S. Petersen: CALPHAD, 2009, vol. 33, pp. 295-311.

8. J.O. Andersson, T. Helander, L. Höglund, P. Shi, and B. Sundman: CALPHAD, 2002, vol. 26, pp. 273-312.

9. A.D. Pelton and C.W. Bale: Metall. Mater. Trans. A, 1986, vol. $17 \mathrm{~A}$, pp. $1211-15$

10. C.W. Bale and A.D. Pelton: Metall. Mater. Trans. A, 1990, vol. 21A, pp. 1997-2002.

11. Steelmaking Data Sourcebook: The Japan Society for Promotion of Science, The 19th Committee in Steelmaking, Gordon and Breach Science Publishers, New York, 1988.

12. G.K. Sigworth and J.F. Elliott: Metals Sci., 1974, vol. 8, pp. 298 310.

13. I.-H. Jung, S.A. Decterov, and A.D. Pelton: Metall. Mater. Trans. B, 2004, vol. 35B, pp. 493-507.

14. T. Miki and M. Hino: ISIJ Int., 2005, vol. 45, pp. 1848-55.

15. Y.-M. Muggianu, M. Gambino, and J.-P. Bros: J. Chim. Phys., 1975, vol. 72, pp. 83-88.

16. A.D. Pelton and P. Chartrand: Metall. Mater. Trans. A, 2001, vol. $32 \mathrm{~A}$, pp. $1355-60$

17. A.D. Pelton, S.A. Degterov, G. Eriksson, C. Robelin, and Y. Dessureault: Metall. Mater. Trans. B, 2000, vol. 31B, pp. 651-59.

18. Y.-B. Kang, A.D. Pelton, P. Chartrand, and C.D. Fuerst: CALPHAD, 2008, vol. 32, pp. 413-22.

19. I.-H. Jung: McGill University, Montreal, QC, Canada, Unpublished research, 2014.

20. A.T. Phan, M.K. Paek, and Y.-B. Kang: Acta Mater., 2014, vol. 79 , pp. $1-15$.

21. K. Shubhank and Y.-B. Kang: CALPHAD, 2014, vol. 45, pp. $127-37$.

22. S. Cui, M. Paliwal, and I.H. Jung: Metall. Mater. Trans. E, 2014, vol. 1E, pp. 67-79.

23. A. Shukla and A.D. Pelton: J. Phase Equilib. Diff., 2009, vol. 30, pp. 28-39.

24. M.K. Paek, J.J. Pak, and Y.-B. Kang: CALPHAD, 2014, vol. 46, pp. $92-102$.

25. J.-P. Harvey: Masters Thesis, Ecole Polytechnique, Montreal, QC, Canada, 2006.

26. P. Chartrand: Ecole Polytechnique, Montreal, QC, Canada, Unpublished research, 2004. 
27. M.K. Paek, K.H. Do, Y.-B. Kang, I.-H. Jung, and J. J. Pak: Unpublished research, 2016.

28. A.D. Pelton: CALPHAD, 2001, vol. 25, pp. 319-28.

29. A.T. Dinsdale: CALPHAD, 1991, vol. 15, pp. 317-425.

30. P. Gustafson: Scand. J. Metall., 1985, vol. 14, pp. 259-67.

31. K. Frisk: CALPHAD, 1987, vol. 11, pp. 127-34

32. K. Frisk: CALPHAD, 1991, vol. 15, pp. 79-106.

33. R.D. Pehlke and J.F. Elliott: Trans. Met. Soc. AIME, 1960, vol. 218, pp. 1088-101.

34. E.J. Kim, B.D. You, and J.J. Pak: Metall. Mater. Trans. B, 2001, vol. 32B, pp. $659-68$.

35. K.G. Leewis and A. McLean: Can. Metal. Q., 1979, vol. 18, pp. 333-40.

36. W.Y. Kim, J.O. Jo, T.I. Chung, D.S. Kim, and J.J. Pak: ISIJ Int., 2007, vol. 47, pp. 1082-89.

37. A. Sieverts and G. Zapf: J. Phys. Chem. A, 1935, vol. 172A, pp. 314-15.

38. V.C. Kashyap and N. Parlee: Trans. Met. Soc. AIME, 1958, vol. 212 , pp. $86-91$

39. D.W. Gomersall, A. McLean, and R.G. Ward: Trans. Met. Soc. AIME, 1968, vol. 242, pp. 1309-15.

40. R.P. Yadav and S.P. Pednekar: Metall. Eng. IIT Bombay, 1971, vol. 2, pp. 14-17.

41. Y. Tsu and T. Saito: Reas. Inst. Mineral Dressing Metall., Tohoku University, 1971, vol. 27, pp. 151-160.

42. S.W. Lee and H.Y. Young: J. Korean Inst. Met., 1984, vol. 22, pp. 789-93.

43. F. Ishii, S. Ban-Ya, and T. Fuwa: Tetsu-to-Hagané, 1982, vol. 69 , pp. $946-55$.

44. J. Chipman and D.W. Murphy: Trans. AIME, 1935, vol. 591, pp. 179-86.

45. W.Y. Kim, J.G. Kang, C.H. Park, J.B. Lee, and J.J. Pak: ISIJ Int., 2007, vol. 47, pp. 945-54.

46. D.H. Kim, M.S. Jung, H. Nam, M.K. Paek, and J.J. Pak: Metall. Mater. Trans. B, 2012, vol. 43B, pp. 1106-12.

47. J.M. Jang, S.H. Seo, M. Jiang, M.K. Paek, X. Wang, and J.J. Pak: ISIJ Int., 2014, vol. 54, pp. 32-36.

48. H. Schenck, M.G. Frohberg, and H. Heinemann: Arch. Eisenhüttenwes., 1962, vol. 33, pp. 593-600.

49. Y. Kasamatsu and S. Matoba: Tetsu-to-Hagané, 1959, vol. 45, pp. $100-105$.

50. A. Satir-Kolorz and H. Feichtinger: Z. Metallkd., 1991, vol. 82, pp. 689-97.

51. H. Feichtinger, A. Satir-Kolorz, and Z. Xiao-Hong: Proc. High Nitrogen Steels, Inst. Met. Soc. Française, Lille, France, 1988, pp. $75-80$.

52. W.Y. Kim, C.O. Lee, C.W. Yun, and J.J. Pak: ISIJ Int., 2009, vol. 49, pp. 1668-72.

53. T.I. Chung, J.B. Lee, J.G. Kang, J.O. Jo, B.H. Kim, and J.J. Pak: Mater. Trans., 2008, vol. 49, pp. 854-59.

54. S. Maekawa and Y. Nakagawa: Tetsu-to-Hagané, 1960, vol. 46, pp. $748-53$.

55. H. Schenck, M.G. Frohberg, and H. Graf: Arch. Eisenhüttenwes., 1959 , vol. 30, pp. 533-37.

56. C. Qiu and A.F. Guillermet: Z. Metallkde., 1993, vol. 84, pp. 1122.

57. S.Z. Beer: Trans. AIME, 1961, vol. 221, pp. 2-8.

58. N.A. Gokcen: Trans. AIME, 1961, vol. 221, pp. 200-201.

59. V.P. Perepelkin: Izv. Vysshikh Uchebnykh Zaved. Chernaya Metall., 1966, vol. 9, pp. 88-93.

60. G.J. Kor: Metall. Mater. Trans. B, 1978, vol. 9B, pp. 97-99.

61. G.M. Grigorenko, Y.M. Pomarin, V.I. Lakomskii, and A.V. Sherevera: Izv. Akad. Nauk SSSR Metall., 1974, vol. 6, pp. 11-15.

62. I.B. Baratashvili, V.P. Fedotov, A.M. Samarin, and V.M. Berezhiani: Dokl. Akad. Nauk SSSR, 1961, vol. 139, pp. 1354-55.

63. J.M. Jang, J.Y. Eom, M. Jiang, M.K. Paek, and J.J. Pak: ISIJ Int., 2013, vol. 53, pp. 768-73.

64. K. Iwase: Sci. Rep. Tohoku Imp. Univ. Ser. 1, 1926, vol. 15, pp. 531-66.

65. A. Schweighofer and S. Kúdela: Kovové Mater., 1974, vol. 12, pp. 95-107.

66. A. Schweighofer and S. Kúdela: Kovové Mater., 1974, vol. 12, pp. 268-79.

67. H.A. Wriedt: Bull. Alloy Phase Diagr., 1986, vol. 7, pp. 329-33.
68. J. Czochralski: Z. Metallkd., 1922, vol. 14, pp. 277-85.

69. W. Claus: Z. Metallkd., 1929, vol. 21, pp. 268-69.

70. X. Ma, C. Li, F. Wang, and W. Zhang: CALPHAD, 2003, vol. 27 , pp. $383-88$.

71. J.H. Shin, J. Lee, D.J. Min, and J.H. Park: Metall. Mater. Trans. $B, 2011$, vol. 42B, pp. 1081-85.

72. H. Wada, S.W. Lee, and R.D. Pehlke: Metall. Mater. Trans. B, 1986, vol. 17B, pp. 238-39.

73. F. Ishii, S. Ban-Ya, and T. Fuwa: Tetsu-to-Hagané, 1982, vol. 68, pp. 1551-59.

74. H. Wentrup and O. Reif: Arch. Eisenhüttenwes., 1949, vol. 20, pp. 359-62.

75. J.M. Jang, M.K. Paek, and J.J. Pak: Hanyang University, Ansan, South Korea, Unpublished research, 2016.

76. R.A. Dodd and N.A. Gokcen: Trans. Met. Soc. AIME, 1961, vol. 221 , pp. $233-36$

77. I.B. Baratashvili, V.P. Fedotov, A.M. Samarin, and V.M. Berezhiani: Dokl. Akad. Nauk SSSR, 1961, vol. 140, pp. 423-25.

78. J.C. Rawers and N.A. Gokcen: J. Phase Eqilib., 1993, vol. 14, pp. $179-83$

79. J.M. Jang, S.H. Seo, Y.D. Kim, H.J. An, and J.J. Pak: ISIJ Int., 2014, vol. 54, pp. 1578-83.

80. H. Wada and R.D. Pehlke: Metall. Mater. Trans. B, 1978, vol. 9B, pp. 441-48.

81. D.B. Evans and R.D. Pehlke: Trans. Met. Soc. AIME, 1964, vol. 230 , pp. 1651-56.

82. V.F. Isaev and A.N. Morozov: Izv. Vysshikh Uchebnykh Zaved. Chernaya Metall., 1962, vol. 5, pp. 57-60.

83. S. Maekawa and Y. Nakagawa: Tetsu-to-Hagané, 1960, vol. 46, pp. $1438-41$.

84. M. Hillert and S. Jonsson: Metall. Mater. Trans. A, 1992, vol. $23 \mathrm{~A}$, pp. $3141-49$.

85. J. Miettinen: Report TKK-MT-193, Helsinki University of Technology Publications in Mat. Sci. Metall., Helsinki, Finland, 2007, pp. $1-27$

86. M.W. Chase, Jr: NIST-JANAF Thermochemical Tables, AIP, Woodbury, NY, 1998.

87. D.L. Hildenbrand and W.F. Hall: J. Phys. Chem., 1963, vol. 67, pp. 888-93.

88. A.S. Bolgar, S.P. Gordienko, E.A. Ryklis, and V.V. Fesenko: Khim. Fiz. Nitridov, G.V. Samsonov, ed., Naukova Dumka, Kiev, 1968, pp. 151-56.

89. L.H. Dreger, V.V. Dadape, and J.L. Margrave: J. Phys. Chem., 1962, vol. 66, pp. 1556-59.

90. W. Nakao, H. Fukuyama, and K. Nagata: J. Am. Cerm. Soc., 2002, vol. 85, pp. 889-96.

91. M.K. Paek, J.M. Jang, H.J. Kang, and J.J. Pak: ISIJ Int., 2013, vol. 53 , pp. 535-37.

92. C.A. Neugebauer and J.L. Margrave: Z. Anorg. Allgem. Chem., 1957, vol. 290, pp. 82-86.

93. A. D. Mah, E. G. King, W. W. Weller, and A. U. Christensen: U.S. Bureau of Mines Rept. Invest. 5716, 1961.

94. J.C. Vaughan and J. Chipman: AIME Trans., 1940, vol. 140, pp. 224-31.

95. V.I. Yavoiskii, A.G. Svyazhin, A.F. Vishkarev, and G.M. Chursin: Proc. Mosc Inst. Steel Alloys Mosc. Metall., 1973, vol. 74 , pp. $21-31$.

96. O. Opravil and R.D. Pehlke: Trans. Am. Foundrym. Soc., 1969, vol. 176, pp. 415-21.

97. H. Du and M. Hillert: Z. Metallkd., 1991, vol. 82, pp. 310-16.

98. E. Chen, S. Wang, Y. Dong, B. Wu, and Y. Zhou: J. Iron Steel Reas. Int., 2007, vol. 14, pp. 21-24.

99. M. Uda and R.D. Pehlke: Cast Met. Res. J., 1974, vol. 10, pp. $30-38$.

100. D. Bouchard and C.W. Bale: Metall. Mater. Trans. B, 1995, vol. 26B, pp. 467-84.

101. J.M. Jang, M.K. Paek, and J.J. Pak: Hanyang University, Ansan, South Korea, Unpublished research, 2016.

102. G.K. Sigworth and J.F. Elliott: Can. Met. Q., 1974, vol. 13, pp. $455-61$.

103. G.K. Sigworth and J.F. Elliott: Can. Met. Q., 1976, vol. 15, pp. 123-27.

104. G.K. Sigworth, J.F. Elliott, G. Vaughn, and G.H. Geiger: Can. Met. Q., 1977, vol. 16, pp. 104-10. 